Originalveröffentlichung in: Zeitschrift für Assyriologie und Vorderasiatische Archäologie 98, 2008, S.45-99

\title{
Über den Wert von Befestigungsanlagen
}

\author{
von Andreas Fuchs - Tübingen
}

\begin{abstract}
The siege-techniques of the Neo-Assyrian empire were much less advanced than commonly held. No less than two or three years of incessant efforts were necessary to reduce a large fortress or city. Especially the well fortified centers of the petty kingdoms in Syria and the Levant proved to be virtually impregnable against Assyrian attacks. When they fell at last, it was more for political than military reasons: During the second half of the $8^{\text {th }}$ century most of the Syrian kings became vassals of Assyria. While the kings benefitted greatly from their relationship to the Assyrian overlord, their subjects had to bear all the burdens. Wherever this happened, the resulting alienation of the king from his people destroyed the social cohesion necessary for defence and paved the way for an effortless conquest by the Assyrians.
\end{abstract}

Im Jahre 856 schien es ganz so, als müssten binnen kurzem all die kleinen, aber sehr reichen Kleinkönigtümer des syrischen Raumes dem Assyrerkönig Salmanassar III. erliegen. Mit dem faktischen Ende des Reiches von Bìt-Adini war der Sperrriegel beseitigt, der die Assyrer vom Gebiet westlich des Euphrat noch hätte fernhalten können. In diesem Jahr 856 hat Salmanassar damit begonnen, die Stadt Til-Barsip zu einem festen Stützpunkt auszubauen. Er besaß damit einen wichtigen Euphratübergang, der sich als Einfallstor für weitere Eroberungszüge in die Tiefe des syrischen Raumes von selbst anbot. Vor allem aber verfügte der Assyrerkönig über die gewaltigste Streitmacht seiner Zeit und er hatte alle Zeit der Welt, denn es gab keinen Feind, den er fürchten musste oder der ihn hätte ablenken können, denn im gleichen Jahr hatte die einzige andere aufstrebende Macht, das urartäische Reich, ein ausgesprochen klägliches Debüt gegeben. Die Aussichten für den assyrischen König hätten kaum besser sein können.

Bei seinen Vorstößen aber traf Salmanassar sehr bald, im Jahre 853, auf Adad-idri d.h. Hadad-ezer, den König von Damaskus, ${ }^{1}$ der ihm an der Spitze einer Koalition syrischer Fürsten die Stirn bot und während der nächsten Jahre selbst die massivsten assyrischen Angriffe zu parieren wusste.

Das war zwar über die Maßen ärgerlich, doch sprachen alle Umstände dafür, dass die Koalition am Ende doch unterliegen musste:

1 Yamada (2000, 311 Anm. 13). 
Da die Koalition sich allein auf die Verteidigung beschränkte, überließ sie die Initiative Salmanassar, der für seine Angriffe jeweils einen Zeitpunkt wählen konnte, der für ihn günstig, für die Koalition zugleich aber der ungünstigste war. Wer von vornherein darauf verzichtet, das Unheil dort zu bekämpfen, wo es herkommt, kann außerdem bestenfalls Zeit, nicht aber einen solchen Krieg gewinnen. Mochte Salmanassar hundert Schlachten verlieren, so konnte er sich jedesmal in sein Gebiet zurückziehen und dort ungestört seine Verbände wieder auffüllen. Siegte jedoch er auch nur ein einziges Mal, so würde er der Koalition keine Pause gönnen, sondern solange nachstoßen, bis er sie samt und sonders ruiniert hätte.

Die Koalition war darüberhinaus nur ein loses Sammelsurium ansonsten eigenständiger und gleichberechtigter Könige. Es können aber innerhalb eines derartigen Bündnisses unmöglich alle Partner denselben Vorteil davon haben, ebenso werden einige von ihnen größere Schäden erleiden als andere. Da alle Bündnispartner prinzipiell eigenständig sind, können sie sich nie sicher sein, ob nicht der eine oder andere plötzlich auf die Seite des Feindes hinüberwechseln wird, weil er sich davon mehr verspricht. Rangstreitigkeiten und wiederaufflammende alte Zwiste werden ein Übriges tun, ein solches Bündnis über kurz oder lang von selbst zu zerstören.

Im Gegensatz dazu bildete das assyrische Reich einen in sich ruhenden, monolithischen Block aus Dienern und Sklaven des Königs, deren keiner eine eigenständige Außenpolitik betreiben konnte. Für Salmanassar hieß es also zuversichtlich sein und in Abständen neue Vorstöße zu unternehmen. ${ }^{2}$ Misstrauen und Neid, die beiden mächtigsten Verbündeten eines jeden, der allein gegen ein Bündnis zahlreicher Gegner kämpft, würden ihm den Weg mit der Zeit schon ebnen und die Koalition von innen her sprengen.

Der erhoffte Umschwung trat ein, als sich mit dem Tod des Hadadezer zwischen 845 und 841 die Koalition sogleich auflöste. ${ }^{3}$ Nun war der Weg für Salmanassar frei, der im Jahre 841 nach Syrien zog, um seine Chance zu nutzen. Der neue König Hazael stellte sich ihm entgegen, wurde aber erwartungsgemäß geschlagen und die Assyrer verfolgten die Reste seines Heeres bis nach Damaskus. ${ }^{4}$

Wer den Gang der Ereignisse anhand der Inschriften Salmanassars bis zu diesem Punkt mitverfolgt hat, würde gleich in der nächsten Zeile die

\footnotetext{
${ }^{2}$ Angriffe erfolgten 853, 849, 848 und 845, zu den Quellen siehe Yamada (2000, 143-183).

3 Yamada (2000, 189).

4 Yamada $(2000,185 \mathrm{ff}$.$) .$
} 
Meldung vom Fall der Stadt erwarten. Stattdessen aber steht da zu lesen, dass sich Salmanassar damit begnügen musste, die Umgebung von Damaskus zu verwüsten und anschließend unverrichteter Dinge von dannen zu ziehen. ${ }^{5}$ Auch bei zwei späteren Angriffen, die 838 und 837 unternommen wurden, gelang die Einnahme von Damaskus nicht. Die Inschriften berichten lediglich über die Einnahme kleinerer Siedlungen und sind ansonsten bemüht, die wenig ruhmvollen Geschehnisse eher zu verschleiern. ${ }^{6}$ Der König von Damaskus hat somit in seiner Hauptstadt nicht weniger als drei Mal der assyrischen Militärmacht widerstanden, und das, nachdem sein Heer geschlagen und er selbst ohne Verbündete war und obgleich die Ebene, in der Damaskus lag, die Verteidigung keineswegs begünstigte. Es ist ersichtlich, dass sich die Stadt Damaskus sehr viel effektiver der Assyrer erwehren konnte als das damaszenische Heer.

Ein genauerer Blick in die Inschriften Salmanassars zeigt, dass dieses Scheitern der mächtigsten Militärmaschinerie ihrer Zeit keineswegs außergewöhnlich oder einmalig war. Auch anderswo ist es den Assyrern damals nicht besser ergangen:

In Que setzte Salmanassar 831 nach drei Jahren Krieg einen König in Tarsus ein. ${ }^{7} \mathrm{Da}$ jedoch sowohl die Herrscher von Que wie auch ihre unmittelbaren Nachbarn für dieses Land Bezeichnungen verwenden, die unmissverständlich auf die Stadt Adana hindeuten, ${ }^{8}$ muss folglich Adana und nicht Tarsus die Hauptstadt von Que gewesen sein. Wenn also Salmanassar seinen Favoriten stattdessen in Tarsus zum König machte, so nur deshalb, weil er zu mehr nicht in der Lage war und weil ihm Adana genauso widerstanden haben muss wie zuvor Damaskus. ${ }^{9}$ Tatsächlich ergibt der Vergleich zwischen den Inschriften Salmanassars und den Eponymenchroniken für das vorangegangene Jahr 832 eine verdächtige Unregelmäßigkeit. Während nämlich die Eponymenchroniken für das Jahr 832 einen Feldzug gegen Que vermelden, existiert besagtes Jahr in den Inschriften überhaupt nicht und wird bei der Jahreszählung übersprungen, in ganz ähnlicher Weise übrigens, wie die Inschriften auch eines jener Jahre übergehen, in denen Salmanassar Damaskus erfolglos angegrif-

5 Grayson (1996, 54 iii 45-iv 4 und 77: 122'-130'). Siehe auch Yamada $(2000,186)$.

6 Yamada $(2000,205-209)$.

7 Yamada $(2000,218-221)$.

8 Hawkins (1995, 98), Tropper (1993, 153: S16).

$9 \mathrm{Da}$ in keinem Text Salmanassars davon berichtet wird, dass Katê, damals der regierende König von Que und Gegner Salmanassars, besiegt, gefangen oder getötet worden sei, ist davon auszugehen, dass Katê sich weiterhin in Adana hielt. Anders als Yamada (2000, 220f.) glaube ich daher nicht, dass Salmanassar mit dem Resultat des Feldzuges von 831 zufrieden war. 
fen hat. ${ }^{10}$ Es ist daher mehr als nur wahrscheinlich, dass im schamvoll verschwiegenen Jahre 832 eine missglückte Belagerung von Adana stattgefunden hat. Wenn Verfasser assyrischer Königsinschriften, die es ja ansonsten durchaus verstanden, selbst marginale Ereignisse wunderbar aufzubauschen, sich in diesem Falle mit ihrer Kunst am Ende sahen und dem Ereignis rein gar nichts Rühmliches mehr abgewinnen konnten, so muss diese Unternehmung einen außerordentlich schmählichen Verlauf genommen haben! Kein Wunder also, dass der Name der Stadt Adana in keinem Text Salmanassars zu finden ist, denn assyrische Inschriften bevorzugen es, Städte, vor denen der König gescheitert war, mit Schweigen zu übergehen.

So begegnet auch der Name Karkemiš in den Inschriften Salmanassars allein deshalb, weil hier der Name des Königreiches mit dem seiner Hauptstadt identisch war. Die eigentliche Stadt Karkemiš hat Salmanassar nie anzugreifen gewagt, folglich findet die Stadt als solche keine Erwähnung.

Dass dies die Regel war, zeigt sich am Beispiel des Königreiches BìtAgūsi, wo Hauptstadt und Reich unterschiedliche Namen trugen. Im Jahre 849 hat Salmanassar dort eine Königsstadt mit Namen Arne eingenommen, ${ }^{11}$ weshalb vermutet wurde, dieses Arne müsse damals die Hauptstadt von Bït-Agūsi gewesen sein. ${ }^{12}$ Man muss sich hierbei jedoch vor Augen führen, in welcher Weise sich die damaligen Kleinkönigreiche des syrischen Raumes in ihren jeweiligen Hauptstädten konzentrierten, die zugleich Königsresidenz, Regierungssitz, Handelsplatz, Schatzkammer, Produktionsstätte, Arsenal, Zeughaus und Wohnort der Elite waren. Nach dem Verlust eines solchen Zentrums wäre schlechterdings keine Substanz mehr verblieben, um ein Fortbestehen des Reiches noch zu erlauben. Da Bìt-Agūsi den Verlust von Arne noch um mehr als ein ganzes Jahrhundert überlebt hat, ${ }^{13}$ kann diese Stadt nicht mehr als eine Nebenresidenz gewesen sein, während sich das eigentliche Zentrum gegen Salmanassar behauptet haben muss. Wenn aber Bït-Agūsi als Feind Assyriens überlebte, der Name seiner Hauptstadt in den assyrischen Quellen dieser Zeit nicht erscheint und sich außerdem auch kein direkter Hinweis auf eine Belagerung findet, so war diese Stadt offensichtlich derart fest,

10 Siehe dazu Fuchs $(1998,90)$ und Yamada (2000, 66 sub 838 und 837).

11 Yamada $(2000,166 \mathrm{C})$.

12 Lipiński, (2000, 198).

13 Und das, obgleich unter Adad-nārārī III., Salmanassar IV. und Aššur-dan III. durchaus etliche Feldzüge in den syrischen Raum stattgefunden haben. Bït-Agūsi selbst, bzw. seine Hauptstadt Arpad, war 805 und 754 Ziel assyrischer Angriffe, siehe Millard (1994, 33-42). 
dass Salmanassar ihre Belagerung als ebenso aussichtslos erachtete wie die von Karkemiš. Die eigentliche Hauptstadt von Bït-Agūsi dürfte schon zu dieser Zeit das später bezeugte Arpad gewesen sein, dessen Verteidigungsanlagen derart stark waren, dass noch Tiglatpileser III. drei Jahre zur Eroberung dieser Stadt benötigte. Im Hinblick auf die Verwendung des Begriffes „Königsstadt“ durch assyrische Quellen ${ }^{14}$ lässt sich damit eine Regel formulieren:

Überlebte ein kleines Reich einen assyrischen Angriff, obwohl dort den Inschriften zufolge der betreffende assyrische König eine Königsstadt ( $\bar{a} l$ šarrüti) eingenommen haben will, so ist auszuschließen, dass es sich bei besagter Königsstadt um das eigentliche Zentrum des betreffenden Reiches gehandelt haben kann.

Auf das Königreich Hamat angewendet, bewirkt diese Regel zweierlei: Erstens wird durch sie die ansonsten ja fast zwingende und zugleich wenig überzeugende Annahme hinfällig, Hamat habe sein Zentrum gleich mehrfach hintereinander eingebüßt, wobei der König samt Hof nach jeder Zerstörung der bisherigen Hauptstadt durch die Assyrer in eine andere Stadt umgezogen sei. ${ }^{15}$ Und zweitens erklärt sich dadurch, wie Hamat überleben konnte, obgleich sein Territorium doch als Schauplatz der Kämpfe zwischen Salmanassar und der damaszenischen Koalition herhalten musste und, schlimmer noch, seit 841 ohne den Schutz von Verbündeten dem assyrischen Zugriff ausgeliefert war. Wenn es Salmanassar im Jahre 853 gelungen ist, die als Königsstädte bezeichneten Siedlungen Adennu, Parga, Argana und Qarqar einzunehmen, ${ }^{16}$ so kann der Regel folgend keine dieser Städte das eigentliche Zentrum des Königreiches Hamat gewesen sein. Dasselbe gilt um so mehr für die beiden 848 zerstörten Städte Aštammaku und Apparazu, die noch nicht einmal als Königsstädte bezeichnet werden. ${ }^{17}$ Stattdessen ist wie im Falle von Karkemiš auch bei Hamat davon auszugehen, dass der Name des Landes und seiner Hauptstadt identisch war. Bleibt die Stadt Hamat in den Berichten Salmanassars unerwähnt, so deshalb, weil er sie ebensowenig an-

14 Zur Kategorisierung von Siedlungen in assyrischen Quellen siehe Liverani (1992, $125 \mathrm{ff}$.) am Beispiel der Inschriften Assurnasirpals II.

15 Wer mit Ikeda (1979, 82f.) diese Ansicht vertreten möchte, der möge vor allem erklären, wie es dem König und der Elite des Reiches Hamat denn nur gelungen sein soll, den assyrischen Belagerern jedesmal wieder zu entschlüpfen. Sie müssten doch eigentlich in der Hauptstadt eingeschlossen gewesen sein und nach deren Fall als Gefangene Salmanassars geendet haben!

16 Yamada (2000), 144 Annals $3 \mathrm{~F}$ und G und 153-156).

17 Yamada $(2000,170 \mathrm{E}$ und $\mathrm{G})$. 
zugreifen gewagt hat wie Karkemiš und Arpad. Die Zerstörung der in den Inschriften erwähnten Nebenresidenzen haben dem Reich Hamat sicher schweren Schaden zugefügt, doch konnte es sich davon wieder erholen, weil ja das Zentrum, der Lebensnerv, nicht getroffen war.

Vor anderen Hauptstädten wie Artulu und Hubušnu in Tabāl ${ }^{18}$ oder Tagarimmu (bzw. Til-Garimmu), der Zweitresidenz des Reiches Melidu, ${ }^{19}$ erschien Salmanassar zwar mit Drohgebärden, zog aber bereitwillig ab, sobald er vom jeweiligen Herrn der Stadt die erhofften Geschenke bekam. Diese Städte standen dabei sicher nicht in unmittelbarer Gefahr, im Sturm genommen zu werden, die geleisteten Zahlungen erfolgten wohl eher zu dem Zweck, den Assyrer von der Verwüstung des Umlandes abzuhalten. ${ }^{20}$ Es lässt sich gar nicht sagen, wie oft sich der Assyrerkönig allein zu dem Zweck vor eine Stadt gelegt haben mag, um von ihr Zahlungen mit der Drohung zu erpressen, sich andernfalls im Umland gründlich auszutoben. In den Inschriften klingt es dann zwar immer so, als habe er nach geleisteter Zahlung aus reiner Gnade von seinem Opfer abgelassen - und das ist bei Inschriften, die zum Lobe des Herrschers verfasst wurden, auch gar nicht anders zu erwarten - es darf aber bezweifelt werden, ob im konkreten Fall die tatsächliche Eroberung der jeweils betroffenen Stadt überhaupt im Bereich des Möglichen gelegen hat.

Salmanassar war aber nicht nur gegen die großen Zentren machtlos, sondern er konnte auch gegen manch kleinere befestigte Subzentren, wie etwa die Königsstadt Pahri in Que, sofern diese ernsthaft verteidigt wurden, wenig bis garnichts ausrichten. ${ }^{21}$

Das soll nun aber nicht heißen, dass die Assyrer hilflos oder harmlos gewesen wären. Und wir wollen auch nicht zu jenen gehören, die pauschal sämtliche Angaben der Inschriften in Bausch und Bogen als erfunden, als bloße Übertreibung oder gar als Phantasiegespinste abtun. Wären diese Quellen derart verlogen, wie es oft behauptet wird, so wären wir gar nicht in der Lage, mit ihrer Hilfe die Möglichkeiten der Assyrer in der Art einzugrenzen, wie wir es hier versuchen. Wenn die Inschriften Siedlungen namentlich aufzählen, die Salmanassar und natürlich auch die übrigen assyrischen Könige zerstört haben wollen, so spricht der

\footnotetext{
18 Yamada (2000, 211f.).

19 Yamada $(2000,214 \mathrm{f}$.$) .$

20 Bezeichnenderweise kommt Tuatti, der König von Tabāl, noch nicht einmal persönlich aus dem umzingelten Artulu heraus, um Salmanassar seine Geschenke zu bringen, sondern schickt lediglich seinen Sohn, siehe Yamada (2000, 211). Das war ein klares Zeichen dafür, dass die Unterwerfung des Tuatti alles andere als vollständig war!

21 Yamada $(2000,202)$.
} 
Umstand, dass in solchen Aufzählungen gerade die Namen der bedeutenden Städte fehlen, durchaus für die Glaubhaftigkeit der Berichte.

Ein Kleinkönig, der sich auf eine Invasion des übermächtigen Assyrerkönigs vorbereitete, wird seine geringen Kräfte auf die Verteidigung vor allem der Haupstadt und vielleicht einiger weniger bedeutender Festungen konzentriert haben, um wenigstens diese schützen zu können. Alle übrigen Siedlungen, darunter vielleicht auch so manche durchaus ansehnliche, befestigte Stadt, die gegen einen Nachbarkönig von vergleichbarer Stärke sehr wohl verteidigt worden wäre, wird man notgedrungen offengelassen haben. Die Erfolge der Assyrer werden oft genug in der Zerstörung eben solcher unverteidigter Siedlungen bestanden haben, deren Bewohner geflohen oder evakuiert worden waren. Darüberhinaus darf man den assyrischen Quellen auch wohl glauben, dass kleinere Festungen erfolgreich belagert und erstürmt worden sind. ${ }^{22}$

Die entscheidenden Faktoren, die eine effektive Verteidigung ermöglichten, bestanden neben dem Vorhandensein von Verteidigungswerken in der Lage der jeweiligen Siedlung und in ihrer Größe. Wie das Beispiel von Damaskus zeigt, war eine große Einwohnerzahl durchaus geeignet, die Mängel einer ansonsten ungeschützten Lage mehr als auszugleichen. Die Gründe sind offensichtlich, denn je mehr Bewohner eine Stadt be$\mathrm{sa} \beta$, desto gewaltigere Befestigungsbauten konnte sie errichten und auch unterhalten, und über desto mehr Verteidiger verfügte sie im Ernstfall. Konnte der Angreifer bei kleineren Anlagen mit wenig zahlreicher Besatzung hoffen, durch ständige Beunruhigung und Beschäftigung der Belagerten diese physisch zu erschöpfen, so war dies bei großen Städten unmöglich, deren Wehrgänge ohnehin niemals alle Verteidiger zugleich hätten fassen können. Hier war es ohne weiteres möglich, ermüdete Kämpfer abzulösen und Verluste zu ersetzen. ${ }^{23}$ Aus diesem Grund hat Salmanassar von den Zentren der zahlreichen syrischen Kleinkönigtümer mit Ausnahme von Til-Barsip kein einziges bezwingen können. Die Zentren aber waren entscheidend, denn fielen diese nicht, so ließen sich auch noch so zahlreiche Eroberungen in ihrem Umland auf die Länge der Zeit nicht halten und waren nutzlos.

Welche Mittel standen den Assyrern nun eigentlich zur Verfügung, eine befestigte Stadt einzunehmen? Hier helfen die erhalten gebliebenen Anfragen an den Sonnengott Šamaš aus dem 7. Jahrhundert weiter. Das Bild, das diese Texte entwerfen, kann als verlässlich gelten, da es weder dem

22 Das judäische Lahiš ist ein Beispiel für eine solche Nebenfestung, die von assyrischen Truppen im Sturm genommen werden konnte, siehe Ussishkin (1982).

23 Siehe auch Fuchs $(2002,596)$. 
Lobe des Königs dienen sollte, noch in anderer Weise für die Nachwelt bestimmt war. Vielmehr geht es da um konkrete, alltägliche Fälle, in denen entweder assyrische Stützpunkte von der Einnahme durch örtliche Feinde bedroht sind oder umgekehrt die Aussichten assyrischer Truppen ermittelt werden sollen, bestimmte gegnerische Festungen einzunehmen. Da sich die Antwort der Gottheit auf ein bloßes Ja oder ein Nein beschränkte, wäre diese ohne Wert gewesen, wenn die gestellte Frage nicht sämtliche für denkbar gehaltene Eventualitäten berücksichtigte, die das erhoffte oder befürchtete Resultat herbeiführen konnten. Man wird folglich davon ausgehen dürfen, dass sich der Fragesteller um eine vollständige Auflistung aller Mittel, Techniken und Situationen bemühte, die geeignet waren, den Fall der betreffenden Stadt zu erreichen. Insgesamt lassen sich fünf Wege zur Einnahme befestigter Plätze unterscheiden:24

1. Im Handstreich, d.h. mühelos, weil der Verteidiger aus Nachlässigkeit (ina šetūti) die drohende Gefahr missachtet hatte und nicht auf eine Belagerung vorbereitet war, so dass akuter Mangel (mēkûtu), besonders Mangel an Kämpfern in ausreichender Zahl (mēkûtu ša șābe ša libbi a ali), die Verteidung der Stadt von vornherein unmöglich machte.

2. Durch Verhandlungen. Dabei konnten schöne Versprechungen gemacht werden (ina pî țăbi u salìm țubbāti / ina dibbì țābūti (...)), deren spätere Einhaltung durch eidlich bekräftigte Verträge zugesichert wurde (ina adê, zakār šum ili u ištari). Gemeint ist wohl, dass den Verteidigern entweder freier Abzug gewährt wurde oder dass der Eroberer und künftige Herr der Stadt den Bewohnern Leib, Leben und Besitz garantierte. Halfen Versprechungen nichts, so ließen sich die Belagerten vielleicht einschüchtern oder mit irgendeinem Druckmittel erpressen (ina si $\hat{u}^{\mathrm{t}} \mathrm{i}$ ), ${ }^{25}$ so dass sie aus Furcht (ina puluhti) aufgaben. So konnte der Belagerer etwa damit drohen, bei Fortsetzung des Widerstandes Baumgärten zu fällen oder gefangene Stadtbewohner zu pfählen.

Verschloss sich der Herr der Stadt den Argumenten des Belagerers, so ließen sich Appelle auch direkt an seine Untertanen richten, um sie gegen ihn aufzuhetzen. ${ }^{26}$ Herrschte Uneinigkeit in der Stadt oder war

24 Die Belegstellen zu den hier zitierten Begriffen sind in Anhang 1 gesammelt.

25 Die Bedeutung von si ûtu ist nicht ganz klar. Die hier verwendete Bedeutung entspricht dem Vorschlag des AHw 1062 r.o.: etwa „Erpressung“?, vgl. CAD S 336f. „harassment" (?).

26 Den berühmtesten Versuch, eine Stadt durch Drohungen und Appelle einzunehmen, stellen die beiden Reden dar, mit denen im Jahre 701 Sanheribs rab saqê das Volk von Jerusalem und Hiskia zur Aufgabe des Widerstandes zu bewegen suchte (2. Könige $18,26-35$ und 19,9-13). 
deren Herrscher bei seinen Leuten verhasst, so mochte es auf diesem Wege gelingen, Aufruhr und Bürgerkrieg gegen ihn anzuzetteln (ina sìhi u bārti).

3. Durch List und Verrat in ihren zahllosen Formen (ina mimma šipir nikilti ša șabāt āli mal bašû).

4. Durch Eindringen mit Waffengewalt (ina danāni / ina epēš kakki qabli u tăhăzi), wobei die folgenden Mittel und Methoden in Frage kamen:

(a) durch Untergraben oder Durchbrechen der Mauern (ina niksi, ina pilsi), d.h. durch das Herausbrechen von Ziegeln bzw. Steinen, um einen Durchlass zu schaffen, oder durch Vortreiben unterirdischer Stollen, die entweder heimlichen Einlass in die Festung selbst ermöglichen sollten oder dazu gedacht waren, die Fundamente eines Mauerabschnittes oder Turmes zu unterminieren, um denselben zum Einsturz zu bringen und also eine Bresche zu schlagen $^{27}$

(b) durch Übersteigen der Mauern mit Sturmleitern (ina simmilti $u$ nabalkatti)

(c) durch Zertrümmern der Mauern mit Hilfe eines Rammbockes, der vom Innern eines gepanzerten Fahrzeuges aus bedient wurde (hier: ina šubî). ${ }^{28}$ Der Rammbock scheint bei Belagerungen die wichtigste Angriffswaffe überhaupt gewesen zu sein. ${ }^{29} \mathrm{Im}$ 9. Jahrhundert wurde er als nappilu oder nāpilu bezeichnet. ${ }^{30}$ Auch der sehr allgemein gehaltene Ausdruck ina kakki danni „mit mächtiger Waffe“, wird wohl am ehesten dieses Gerät meinen. ${ }^{31}$ Der Rammbock und das ihn umgebende gepanzerte Fahrzeug ist die am häufigsten abgebildete Belagerungsmaschine der neuassyrischen Zeit, wobei die Darstellungen des 9. Jahrhunderts stets nur ein einzelnes, offenbar sehr großes Gerät zeigen (Abbildungen 1 und 2), während im 8. und 7. Jahrhundert zwar kleinere Fahr-

27 Siehe dazu Anhang 2.

28 AHw 412 jāšibum, wāšibum, CAD A/II 428 f. ašibu. Die Rekonstruktion eines solchen Fahrzeugs der Zeit Sanheribs, die Ussishkin (1982, 101 Abb. 79) vorschlägt, kann nicht überzeugen, da es als nach oben hin offen und ungeschützt dargestellt wird, obwohl gerade die im selben Band wiedergegebenen Lahiš-Reliefs sehr eindrücklich den von oben herabprasselnden Geschosshagel zeigen.

29 So wird sich hinter dem allgemeinen Begriff nēpešu, „Belagerungsgerät“ (AHw 778 nёреšu (m) 2.b; CAD N/II 170 nёреšu 3.b) zumeist der Rammbock verbergen.

$30 \mathrm{AHw} 738$ nāpilu, CAD N/I 312 nappilu 1 . Zu den dort aufgeführten Belegen siehe jetzt Grayson (1991, 216 iii 53) und Grayson (1996, 191 iv 16').

31 Der Ausdruck erinnert an die Bemerkung Sargons II., er habe mächtige Festungsmauern mit einem (entsprechend) mächtigen Rammbock (ina ašibi danni) zerstört, siehe Fuchs (1994, 91: Ann. 63 f.). 


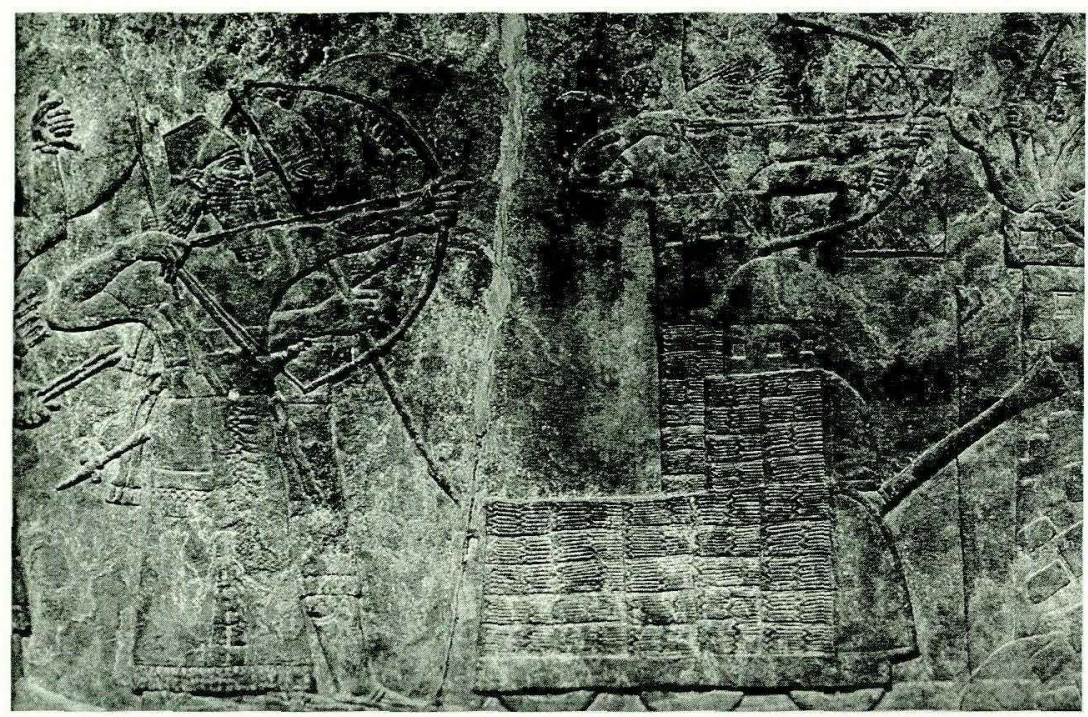

Abb. 1: Rammbock in gepanzertem Fahrzeug im Vordergrund; mit Bogenschütze und Schildträger besetzter Belagerungsturm im Hintergrund. Regierungszeit Assurnasirpals II. Nach Barnett (1975, Tafel 30).

zeuge abgebildet wurden, die dafür aber häufig zu mehreren im Einsatz sind (Abbildung 3). Die Reliefs Sanheribs mit ihrem Sinn für technische Details zeigen deutlich, dass die Fahrzeuge zu dieser Zeit aus vorgefertigten Einzelteilen bestanden, die sich leicht montieren und transportieren ließen. ${ }^{32}$

Um zu verhindern, dass der Verteidiger den Einsatz des Rammbockes störte oder das schützende Fahrzeug in Brand setzte, deckten derweil die Bogenschützen und Schleuderer des Belagerers die Wehrgänge mit Geschossen ein. ${ }^{33}$ Am effektivsten aber ließen sich die Verteidiger niederhalten, wenn man sie aus erhöhter Position beschießen konnte. Dies ermöglichte

32 Assurnasirpal II.: Barnett (1975, Tafeln 28-30). Salmanassar III. (in höchst ungeschickter Darstellung): Billerbeck/Delitzsch (1908, Tafel II Schiene D Abschnitt 3 untere Reihe und Tafel III Schiene I Abschnitt 3). Tiglatpileser III.: Barnett (1975, Tafel 56). Sargon II.: Botta (1849, P1.90. 145 und 147). Sanherib: Barnett (1975, Tafel 78) bzw. Barnett (1998, Pl.328-334. 349-351. 375, vgl. Abbildung 3) mit deutlich wiedergegebenen zerlegbaren Fahrzeugteilen und den sie verbindenden Verschlüssen.

33 Reliefdarstellung besonders Assurnasirpals II. und Sanheribs zeigen dies in eindrücklicher Weise, siehe Barnett (1975, Tafeln 28-29) bzw. Barnett (1998, Pl.322-327). 


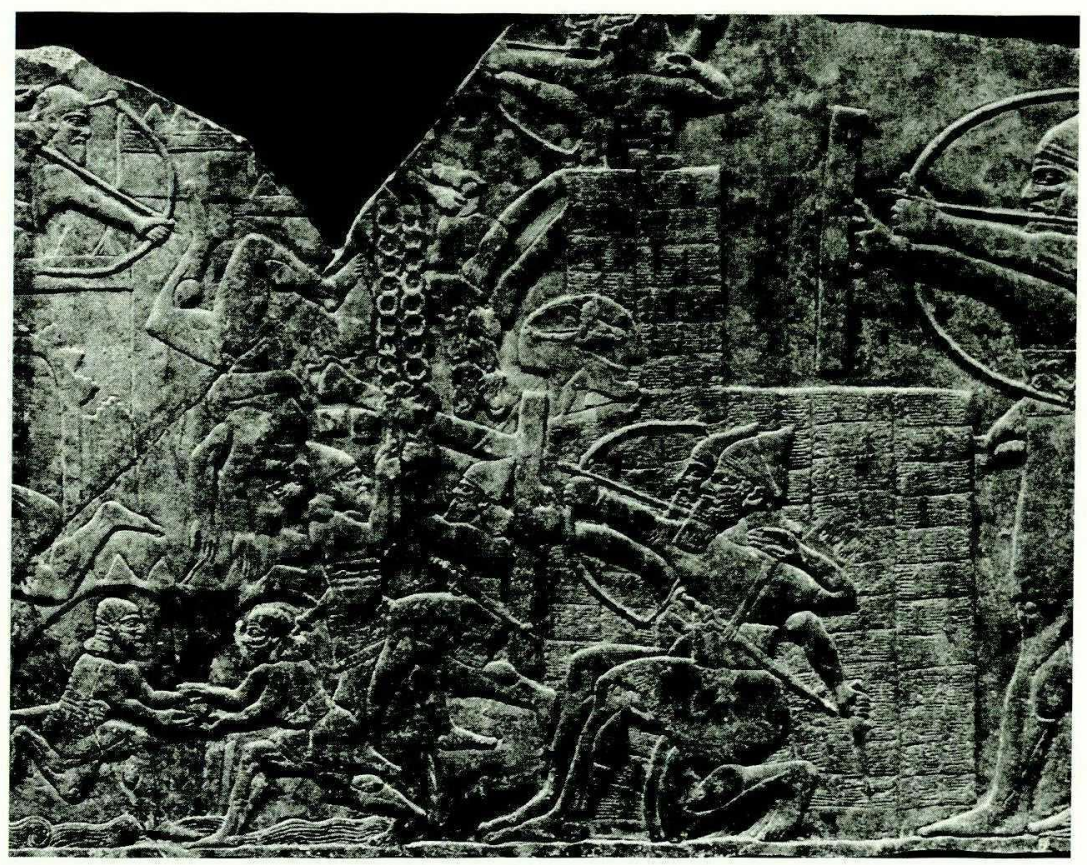

Abb. 2: Drei gleichzeitig angewendete Belagerungsmittel: Anlegen eines Stollens (unten links); hinter den knienden Bogenschützen ein Rammbock in gepanzertem Fahrzeug; hinter diesem ein mit Bogenschützen besetzter Belagerungsturm. Regierungszeit Assurnasirpals II. Nach Barnett (1975, Tafel 28-29).

i. im 9. Jahrhundert der Belagerungsturm (sāpìtu), ${ }^{34}$

ii. der im 8. und 7. Jahrhundert durch den Belagerungsdamm (ina aramme $)^{35}$ ersetzt wurde.

Das Zusammenwirken zwischen dem Rammbock einerseits und dem ihn deckenden Belagerungsturm bzw. -damm war so eng, dass beide Elemente sehr oft gemeinsam aufgeführt werden. ${ }^{36}$

(d) durch „Auflösen“ der Mauer mit Hilfe des Wassers (ina mê mahāhi). Hierbei wird man ein fließendes Gewässer abgedämmt und gesammelt haben, um dann mit einem Schlage die gesamte

34 Siehe Anhang 3.

35 Siehe Anhang 3.

36 In den Anfragen an den Sonnengott lässt sich das in den meisten Fällen nur vermuten, weil an den entsprechenden Stellen zumeist entweder nur das eine oder nur das andere Element erhalten ist. Siehe Anhang 1 sub 4. 


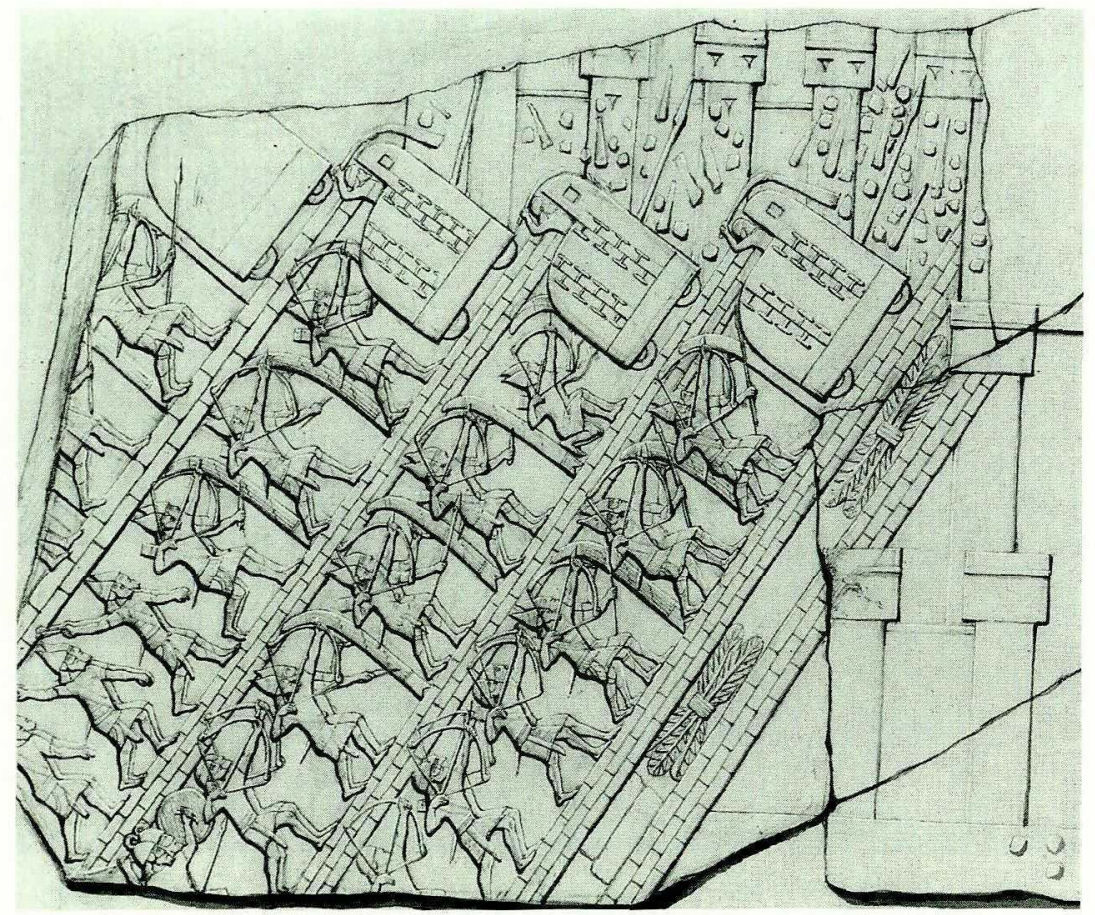

$A b b$. 3: Rammböcke in zerlegbaren Panzerfahrzeugen. Regierungszeit Sanheribs. Nach Barnett (1998, Pl.375).

Masse des aufgestauten Wassers in Richtung auf die belagerte Siedlung freizugeben, so dass Teile ihrer Befestigungsanlagen von der Flut unterspült und weggeschwemmt wurden. Eine derartige Nutzung zerstörerischer Wasserkraft war jedoch nur möglich, wenn ein Gewässer mit dem notwendigen Gefälle in unmittelbarer Nähe des Belagerungsschauplatzes vorhanden und die Festung überdies auch noch tief genug gelegen war, um vom fließenden Wasser überhaupt in der beabsichtigten Weise erreicht werden zu können. Solche Voraussetzungen boten sich nur selten, das prominenteste Beispiel war ausgerechnet die assyrische Hauptstadt Ninive, die unweit der Stelle lag, an der der Hosr die Berge verlässt, und die im Jahre 612 aller Wahrscheinlichkeit nach zum Opfer einer solchen Flutattacke geworden ist. ${ }^{37}$ In den erhalten

37 RIA 9, 427 f. $\S 18$. 
gebliebenen Anfragen wird dieses Mittel jedenfalls nur in einem einzigen Fall erwogen.

(e) Hinter mehreren noch unklaren und selten verwendeten Begriffen aus dem Kontext des Belagerungswesens verbergen sich entweder noch weitere, zusätzliche Belagerungstechniken, oder es handelt sich um bloße Synonyme für längst bekanntes. Der rätselhafte Ausdruck ina lulimititi, den eine der Anfragen enthält, und der ebenfalls ein Mittel zur Einnahme einer Stadt bezeichnen muss, lässt sich ebensowenig deuten wie das in einer Inschrift Sanheribs erwähnte Belagerungsgerät mit dem eigenartigen Namen „Großfliege der Mauer" (nimgalli dūrī). ${ }^{38}$ Nicht eindeutig geklärt ist auch, was sich hinter kalbān(n) ātu verbirgt. ${ }^{39}$

5. Durch Hunger (ina (sunqi hušahhi $u$ ) bubūti) ${ }^{40}$ oder, wenn es gelang, die Wasserzufuhr abzuschneiden, noch wesentlich schneller durch Durst (ina summê). Zur Blockade beließ der Belagerer lediglich einen kleinen Teil seiner Truppen vor der Festung, die durch improvisierte Befestigungsanlagen, man bezeichnet sie am besten als Belagerungsburgen, ${ }^{41}$ gegen Ausfälle der Belagerten geschützt waren. ${ }^{42}$

Stellte nach der hier vorgenommenen Einteilung die Anwendung unmittelbar physischer Gewalt lediglich eine von insgesamt fünf Möglichkeiten dar, eine Stadt zu gewinnen, so wäre dies für Salmanassar III. kein Trost gewesen, denn ihm bot sich nirgendwo und zu keiner Zeit die Möglichkeit, auf schonende, rasche und billige Art und Weise das Zentrum eines der syrischen Königreiche übernehmen zu können. Man ließ sich dort bei weitem nicht in dem Maß von ihm einschüchtern, als er selbst es sich gewünscht hätte und seine Inschriften das behaupten. Ganz im Ge-

38 Borger (1979, 80 v 16). Siehe AHw 790, CAD N/II 234.

39 CAD K 67 „,crowbar-like tool“, AHw 424 „Sturmleitern“.

40 Entgegen den Wörterbüchern wird berûtu, eine weitere Bezeichnung für Hunger, nicht im Zusammenhang mit Belagerungen gebraucht. Der dafür in AHw 123 be/irûtu $(m)$ und CAD B 213 berûtu gebuchte Beleg in den Inschriften Tiglatpilesers ist birütu zu lesen, siehe Tadmor (1994, 162 Anm. zu Summ.7: 21).

41 So nach Böhme et al. (2004, 79). In Frage kommen demnach ebenso die alternativen Begriffe „Gegenburg“, „Schanze“ und „Trutzburg“.

42 Adad-nārārī II. ließ in einem Falle mehrere solcher Belagerungsburgen errichten, die in seinen Inschriften als „Siedlungen“ (äläni) bezeichnet werden, und deren Verwendung er mit sichtlichem Stolz als seine eigene Erfindung ausgibt, siehe Grayson (1991, 150: 54-55). In 266: 9'-10' (ebenfalls Adad-nārārī II.?) ist von sechs solcher ālāni die Rede. Ansonsten werden Belagerungsburgen vollkommen zu Recht als „Festungen“ (bìāti) bezeichnet, die Anlagen Sanheribs vor Jerusalem (Borger 1979, 75 iii 29) ebenso wie die Asarhaddons und Assurbanipals vor Tyros (Borger 1967, 112 Frt. F. Vs.14 bzw. Borger 1996, 28 B ii 62). 
genteil zeigten sich die Könige Syriens zu dieser Zeit durchweg bereit, die Belagerung durch die Assyrer zu riskieren. Schöne Versprechungen halfen nichts, mit List kam man offenbar auch nicht weiter und es scheint sich auch nirgends ein Verräter gefunden zu haben, der die Verteidigung einer Stadt von innen her erfolgversprechend sabotiert hätte. Von den fünf Optionen verblieben Salmanassar damit nur die beiden unangenehmsten, nämlich die Anwendung von Waffengewalt und das Aushungern.

Einzig der Angriff durch aufgestaute Wassermengen (Option 4.d) bot die Möglichkeit, Mauern aus sicherer Entfernung und ohne Risiko für die Angreifer zerstören zu können, aber die Voraussetzungen, solches ins Werk zu setzen, waren nur höchst selten gegeben. Ansonsten aber musste jeder direkte Angriff furchtbare Verluste nach sich ziehen. Es muss einem Selbstmordversuch gleichgekommen sein, gegen den Widerstand eines entschlossenen Verteidigers, der über ausreichend Leute verfügte, Stadtwälle mit Leitern erklimmen zu wollen. Und wer am Bau eines Belagerungsdammes, ${ }^{43}$ am Zuschütten eines Festungsgrabens und dem anschließenden Einsatz eines Rammbockes beteiligt war, oder wer versuchte, am Fuß der Festungsmauer Steine herauszubrechen, sah sich einem Hagel an Pfeilen, Steinen und Brandgeschossen ausgesetzt, von sporadischen Ausfällen der Verteidiger ganz zu schweigen. Und danach stand der Kampf um die entstandene Bresche ja erst noch bevor!44

Weil sie dem Blick des Verteidigers verborgen sind, scheint die Anlage unterirdischer Stollen auf den ersten Blick ungefährlicher zu sein, doch weit gefehlt! Abgesehen davon, dass diese Methode nur zur Anwendung gelangen konnte, wenn es die Bodenbeschaffenheit und die Tiefe des Grundwasserspiegels gestatteten, standen dem Verteidiger durchaus auch hier Abwehrmittel zur Verfügung. Er grub Gegentunnel, und wenn er dann auf die Gänge des Angreifers stieß, konnte er dessen Mineure überfallen und seine Anlagen zum Einsturz bringen. Vielleicht blies er aber auch beißenden Qualm in die engen Kriechgänge oder pumpte sie mit Wasser voll, so dass die dort arbeitenden erstickten oder ertranken. Nein, wirklich angenehm war auch dieses wahrlich nicht.

Doch selbst wenn man die Befestigungen glücklich überwunden hatte, so war es ja keineswegs ausgemacht, dass damit die Kampfhandlungen bereits endeten. Die verwinkelten, unübersichtlichen, engen Straßen alt-

${ }^{43}$ Um seinen Zweck erfüllen zu können, musste der Belagerungsdamm sogar unbedingt in Schussweite der Verteidiger errichtet werden!

44 So hat es Sargon II., obgleich er die Belagerungswerke zum Sturm auf Dür-Jakīn bereits festgestellt hatte, dennoch vorgezogen, den Verteidigern gegen Auslieferung der Stadt freien Abzug nach Elam zu gestatten (Fuchs 1994, 165 ff.: Ann. 357-359b). 
orientalischer Städte eigneten sich ausgesprochen gut dazu, eindringenden Bösewichtern auch hier noch das Leben ungemein schwer zu machen. Die Verfasser eines Briefes an Tiglatpileser III. stellen dies in ihrem Bericht über die Erstürmung wahrscheinlich der Stadt Sapija klar:

„Der König, mein Herr, wird vielleicht sagen: ,(Ach so), die haben ja bloß an den Toren zu kämpfen gehabt!' Aber bei den Göttern des Königs, meines Herrn: Auch noch innerhalb der Stadt sind (unsere Truppen angesichts des heftigen Widerstandes) wirklich und wahrhaftig nur Elle um Elle, Spanne um Spanne vorangekommen, da kann der König fragen (wen er will)!“45

Direkte Angriffe riskierte man daher besser nur bei kleinen oder schlecht verteidigten Siedlungen. Um größeren Städten beizukommen, verblieb damit nur noch das Mittel, sie auszuhungern. ${ }^{46}$ Aber auch das war leichter gesagt als getan, vor allem musste der Angreifer erst einmal sicherstellen, dass er seine eigenen Belagerungstruppen versorgen konnte, um sie lange genug vor der Stadt halten zu können. Da aber die Bewohner einer Stadt ihre Nahrungsmittelvorräte eher innerhalb als außerhalb der Mauern aufbewahrten, mussten im Normalfall den Belagerern die Nahrungsmittel sehr viel schneller ausgehen als den Verteidigern. Mit dieser grundsätzlichen Schwierigkeit, ein großes Heer längere Zeit vor einer Stadt zu verproviantieren, erklärt sich der sichtliche Stolz, mit dem die Inschriften Tiglatpilesers III. verkünden, dass der König im Jahre 733 mit seinem Feldlager ganze 45 Tage lang vor Damaskus gelegen habe. ${ }^{47}$ Über eine solche Zeitspanne mit einem großen Heer vor ein und derselben Festung ausharren zu können, wurde somit als eine auBergewöhnliche, vor allem wohl logistische Leistung betrachtet, die dazu angetan war, die Zeitgenossen zu beeindrucken, selbst dann, wenn diese Hartnäckigkeit noch nicht durch die Einnahme der Stadt Damaskus belohnt wurde, denn diese fiel ja erst im darauffolgenden Jahr.

Allein über den Wasserweg war es möglich, so etwas wie Nachschublinien mit erträglichem Aufwand zu organisieren. Deshalb dürften sich innerhalb Mesopotamiens, wo sich Flüsse und Kanäle nutzen ließen, Belagerungen noch vergleichsweise einfach gestaltet haben, weil man dort den Blockadetruppen alles Notwendige mit Booten und Schiffen zuführen konnte. In Syrien aber bestanden solche Möglichkeiten nicht, hier mussten sich die Belagerer mit dem behelfen, was sie in der Umgebung

\footnotetext{
45 Saggs (2001, 46 ND 2385 19-24). Vgl. Tadmor (1994, 162 Summ.7: 23-25, 196 Summ.11: 16).

46 Und dasselbe galt natürlich auch für all jene Festungen, die aufgrund besonders geschützter Lage für die verfügbaren Angriffsmittel ohnehin unerreichbar waren.

47 Tadmor (1994, 78: Ann.23: 10'-11').
} 
fanden, oder sie waren auf den Landtransport angewiesen, der schwierig, ineffizient und störanfällig war. ${ }^{48}$

Deshalb hat Salmanassar die Belagerung von Til-Barsip zunächst dadurch vorbereitet, dass er zwei Jahre hintereinander das Umland der Stadt verwüstete und die dort heranreifende Ernte vernichtete, ${ }^{49}$ und überdies im weiten Umkreis vorsorglich jeden attackierte und einschüchterte, der als potentieller Retter seines Opfers in Frage gekommen wäre. Als die eigentliche Belagerung gegen Ende 857 begann, litt Til-Barsip längst schon Mangel und es war sichergestellt, dass niemand es wagen würde, die Belagerer zu stören. Um die Blockade aufrecht zu erhalten, ließ Salmanassar vor der Stadt nur einen Teil seines Heeres zurück, der sich vor Ort leicht versorgen ließ, während er mit der Masse seiner Truppen nach Assyrien abzog. Til-Barsip muss während des Winters 857/856 aufgegeben haben, denn im Frühjahr 856 erschien Salmanassar dort lediglich noch zu einer kurzen Visite, um die bereits eroberte Stadt in Augenschein zu nehmen, und stieß anschließend zu seinem Heer, das sich in der Zwischenzeit schon auf dem Weg nach Urarțu befand. ${ }^{50}$

Der Zeitraum von zwei Jahren, den Salmanassar die Eroberung von Til-Barsip kostete, war für die Einnahme einer größeren Stadt durchaus nicht ungewöhnlich, wenn sie durch Hunger bezwungen werden musste: So hat Tiglatpileser III. für die Einnahme von Damaskus ebenfalls zwei Jahre, für die von Arpad sogar drei Jahre benötigt. ${ }^{51}$ Ebenfalls mehr als zwei Jahre lang hielt Assurbanipal die Blockade von Babylon aufrecht, bevor die Stadt schließlich aufgab. ${ }^{52}$ Im Vergleich dazu hatte zuvor Sanherib,

48 In China schrieb Sun Tzu in seinem Traktat über die Kriegskunst zu diesem Problem (Übersetzung nach Sawyer 1993, 160): „The state is impoverished by the army when it transports provisions far off" und: „Thus the wise general will concentrate on securing provisions from the enemy. One bushel of the enemy's foodstuffs is worth twenty of ours; one picul of fodder is worth twenty of ours." Demnach ist damit zu rechnen, dass beim Transport über Land unter den erschwerten Bedingungen des Krieges nur fünf Prozent der losgeschickten Güter ihren Bestimmungsort erreichen! Der Rest wird beim Transport selbst verbraucht, geht verloren, wird verschwendet, verdirbt, wird womöglich vom Gegner abgefangen. Auch im römischen Reich soll der Landtransport vierzig- bis fünfzigmal teurer als der Seetransport gewesen sein, siehe Roth $(1999,199)$.

49 Ein solches Vorgehen steckt wohl hinter den Bemerkungen der Inschriften, Salmanassar habe sowohl in seinem ersten (858) wie auch in seinem zweiten Regierungsjahr (857) Ahuni in dessen Festung Til-Barsip eingeschlossen, siehe Yamada (2000, 78 C, 109: Ann.2 B, 111: Ann.5 B).

so Von allen bisherigen Deutungen des Geschehens ist diese von Yamada (2000, $124 \mathrm{f}$.) vorgeschlagene die bei weitem plausibelste.

51 Tadmor (1994, 232-235 sub 743-741 zu Arpad und 733-732 zu Damaskus).

52 11.IV.650 bis Mitte 648. Assurbanipals Truppen waren so zahlreich, dass er Babylon, Borsippa, Kuta und Sippar gleichzeitig belagern konnte; Frame $(1992,150)$. 
der offenbar Menschenverluste eher als Zeitverlust hinzunehmen bereit war und Babylon stürmen ließ, ${ }^{53}$ die Stadt nach etwas mehr als einem Jahr bezwungen. ${ }^{54}$ Wollte man nicht sehr hohe Verluste bei Sturmversuchen in Kauf nehmen, hatte man für die Einnahme einer großen Stadt somit durchaus zwei bis drei Jahre zu veranschlagen. ${ }^{55}$ Aber selbst das galt nur, wenn es keine Streitkräfte des Verteidigers mehr gab, die den Eroberer bei seinem Werk behinderten. ${ }^{56}$ Und es durfte während dieser Zeit auch nichts geschehen, was eine Unterbrechung der laufenden Operationen erfordert hätte. War der Eroberer etwa zum Abzug gezwungen, weil seine Streitkräfte anderswo dringender benötigt wurden, so erholte sich sein Opfer rasch und er musste, wenn er zurückkehrte und die Belagerung fortführen wollte, wieder ganz von vorne beginnen.

Die Belagerung einer größeren Stadt war also ein langwieriges, elendes und oft frustrierendes Geschäft. Sich darauf einzulassen, wollte vom assyrischen König schon deshalb wohl überlegt sein, weil seine Handlungen ja nicht nur von seinen Feinden, sondern auch von den bereits Unterworfenen aufmerksam beobachtet wurden. Jeder Misserfolg, auch eine erfolglos abgebrochene Belagerung, barg die Gefahr, den einen oder anderen Tributzahler zum Abfall zu ermutigen. Und darüber hinaus war es demütigend und vertrug sich mit der Selbstdarstellung des assyrischen Königs ausgesprochen schlecht, wenn sich der angebliche Liebling sämtlicher Götter und unbesiegbare Weltenherrscher schmählich von dannen trollte, während ihm von den Mauern herab das übermütige Hohn- und Spottgeschrei der erfolgreichen Verteidiger in den Ohren gellte. ${ }^{57}$

53 ina pilši u nabalkatti, Luckenbill (1924, 83: 43-46) bzw. Frahm (1997, T 122).

54 Die Belagerung dauerte ungefähr vom 28.V.690 bis zum 1.IX.689, siehe Frahm (1997, 16).

55 Die Zeitspanne von drei Jahren begegnet bereits im 3. Jahrtausend im Zusammenhang mit der ersten Belagerung, deren Verlauf sich anhand schriftlicher Quellen wenigstens grob mitverfolgen lässt: Obgleich König Uruinimgina von Lagaš in seinem 7. Königsjahr eine entscheidende Niederlage erlitt, die ihn um einen Großteil seines ohnehin winzigen Reiches brachte, konnte er sich in seiner Hauptstadt Girsu noch bis in sein 10. Königsjahr halten (Bauer 1998, 478). Unter besonders widrigen Umständen konnte sich eine Blockade sogar noch weit länger hinziehen. So soll, was von zeitgenössischen Quellen allerdings nicht bestätigt wird, Nebukadnezar II. die Inselstadt Tyros 13 Jahre lang belagert haben (R1A 9, 198 f. Nebukadnezar II. A § 6.2).

56 Solange die damaszenische Koalition noch existierte, hat Salmanassar an die Belagerung einer größeren Stadt nicht einmal denken können.

57 Was osmanische Sultane unternahmen, um sich die demütigenden Begleiterscheinungen eines solchen Rückzuges erträglich zu gestalten, verraten die Memoiren eines Janitscharen aus dem 15. Jahrhundert n.Chr. (Lachmann 1975, 169): „Wenn der Sultan erkennt, dass er mit Hilfe des Sturms nicht zu siegen vermag, befiehlt er, von der Stadt abzulassen, die Kanonen samt Sturmzeug von der Mauer abzuziehen und auf Wagen zu 
Nachdem nun von den Nöten und Schwierigkeiten der belagernden Assyrer die Rede war, ist ausdrücklich zu betonen, dass es für die Bewohner einer Stadt wohl immer eine mindestens ebenso fürchterliche Sache war, belagert zu werden. Abgesehen von der Verwüstung des Umlandes, auf dessen Kultivierung die Stadtbewohner viel Mühe und Zeit verwandt hatten, konnte man sich bis zum endgültigen Abzug der Belagerer niemals zur Gänze sicher sein, ob die Stadt sich tatsächlich würde halten können. Ein gewisses Risiko bestand immer, die Unwägbarkeiten waren hoch, die Folgen im Falle der Niederlage entsetzlich. Es sind mehrere Fälle belegt, in denen die Verteidiger die Belagerung durch die Assyrer überstanden, anschließend aber dennoch Kontakt zum assyrischen König aufnahmen und sich zur Tributzahlung bereit erklärt haben. So hat sich Hiskia nach der Belagerung von Jerusalem (701) vorsichtshalber doch noch dem Sanherib unterworfen, ${ }^{58}$ und ebenso war auch Mugallu nach der erfolgreichen Verteidigung von Melidu (675) bemüht, mit Asarhaddon zu einer Übereinkunft zu gelangen und ist schließlich zum Vasallen Assurbanipals geworden. ${ }^{59}$ Diese nachträglichen Kompromisse zeigen, dass die siegreichen Verteidiger ihren Erfolg durchaus nicht als selbstverständlich betrachteten und es vorzogen, das Schicksal besser nicht noch ein zweites Mal herauszufordern.

Dennoch lässt sich festhalten, dass trotz der bedrohlichen assyrischen Macht für die größeren städtischen Zentren Syriens die Chancen zur Selbstbehauptung alles in allem recht gut standen. Im Hinblick auf ihre Verteidungsfähigkeit lassen sich für die Zeit Salmanassars III. drei Kategorien unterscheiden:

1. Die oberste Kategorie bilden jene Plätze, die durch Lage und Umstände als uneinnehmbar bezeichnet werden können, weil in ihrem Falle ein direkter Angriff nicht möglich war. ${ }^{60}$ Hierzu zählen im syrischen

verladen. Nachdem die Verwundeten aufgesammelt worden sind, lässt er sie vorausschicken. Er selbst verharrt an dem Ort bis zum Anbruch der Nacht. In der Nacht zieht er dann mit dem ganzen Heer fort, damit man ihn aus der Burg oder Stadt nicht verspotte. Auch lässt er stets eine Besatzung zurück, die solche, die sich etwa von der Burg entfernen sollten, (jagen und fangen), damit er sich an diesen etwas rächen könne."

58 Frahm (1997, 10 f.).

59 Parpola/Radner/Baker (1998ff., sub Mugallu).

${ }^{60}$ Festungen dieser Kategorie waren am häufigsten in Urarțu zu finden, wo sie sogar eher die Regel als die Ausnahme bildeten. In den Bergen sicher gelegen, konnten urarțäische Burgen noch nicht einmal ausgehungert werden, da die Assyrer stets vor Anbruch des Winters abziehen mussten. Keine einzige bedeutende urarțäische Burganlage, die von ihrer Besatzung verteidigt wurde, ist jemals von den Assyrern eingenommen worden. Als Beispiel mag die Festung Wajis im Jahre 714 dienen: Obgleich das urarțäische 
Raum nur die Inselstädte Tyros und Arwad, die obendrein auch noch mit ihren Kriegsschiffen das sie umgebende Meer beherrschten. ${ }^{61}$

2. Die zweite Kategorie bilden in Syrien jene Städte, die einem Angriff an sich zugänglich gewesen wären, deren Belagerung Salmanassar aber dennoch nicht wagte, obgleich ihre Herrscher ihm bei einigen Gelegenheiten als Feinde gegenüber standen. Hier sind die Städte Karkemiš, ${ }^{62}$ Arpad, Melidu und Hamat zu nennen. ${ }^{63}$

3. Die dritte Kategorie wird von jenen Städten gebildet, deren Einnahme als schwierig, jedoch nicht als unmöglich erachtet wurde und die deshalb von Salmanassar belagert worden sind. Neben Til-Barsip, dessen Eroberung den Assyrern gelang, gehören in diese Sparte die vergeblich berannten Plätze Damaskus, Til-Garimmu und wahrscheinlich Adana in Que.64

Vielfach lässt sich keine sichere Zuweisung zu den Kategorien 2 oder 3 vornehmen:

Sam'al und Kunulua wären insofern zu Kategorie 2 zu rechnen, als Salmanassar 858 das Umland beider Städte angegriffen hat, ohne die beiden Zentren selbst zu belästigen. Zwei Argumente sprechen allerdings gegen eine eindeutige Zuweisung: Erstens verfolgte der Feldzug von 858 das Ziel, die dortigen Könige soweit einzuschüchtern dass sie die geplante Belagerung von Til-Barsip nicht zu stören wagten. Die Eroberung von Sam'al und Kunulua selbst war also gar nicht beabsichtigt. Zweitens kämpfte das Heer Salmanassars im Gebiet dieser beiden Städte gegen die Truppen einer Koalition syrischer Kleinkönige, deren Anwesenheit zumindest bis zu ihrer Niederlage eine Belagerung verhindert hätte. ${ }^{65}$

Heer eine katastrophale Niederlage erlitten hatte, konnte der siegreiche Sargon II. nicht mehr als eben nur die Vorburg von Wajis einnehmen, die er beim Abzug dann auch gleich wieder räumen musste (Mayer 1983, 98: 299-302).

61 Siehe Anhang 4 sub 6.

62 Siehe auch Anhang 4.

63 Die Reiche, deren Zentren diese Städte bildeten, wurden mehrfach von Salmanassar angegriffen, ohne dass auch nur ein einziges Mal das Zentrum selbst attackiert worden wäre (die Angaben in Klammern beziehen sich auf Yamada 2000): Karkemiš: 857 (110 E'), 849 (166 B) und 848 (170 B). Bīt-Agūsi / Arpad: 849 (166 C), 848 (170 C und G) und 833 (218f.). Melidu: 835 (214-217). Hamat: 853 (144 F und G in Annals 3) und 848 (170 E).

64 Während des Feldzuges gegen das Königreich Melidu (835) bleibt die Hauptstadt gleichen Namens verschont, das Assyrerheer legt sich dafür aber vor Tagarimmu i.e. Til-Garimmu, das im Gegensatz zur Hauptstadt offenbar bezwinglich zu sein schien (Yamada 2000, 214-217). Zu Damaskus und der vermutlich 832 erfolglos versuchten Belagerung von Adana siehe oben.

65 Yamada (2000, 77-108). 
Die Stärke von Kunulua, der Hauptstadt von Unqi/Pattin, lässt sich auch anhand der Vorgänge des Jahres 829 nicht einschätzen, in dem Salmanassar ein Heer gegen diese Stadt entsandte, um den Usurpator Surri abzusetzen. Die Präsenz der assyrischen Truppen führte zum gewünschten Umsturz, doch wurde die Angelegenheit von den Bewohnern der Stadt intern geregelt: Diese verhafteten die "Rebellen“ und lieferten sie an die Assyrer aus, denen anschließend der neue Machthaber Sasi huldigte. Davon, dass etwa assyrische Truppen in die Stadt eingedrungen wären, oder dass man sie hereingelassen hätte, ist keine Rede, das Königreich Unqi/Pattin blieb bestehen. ${ }^{66}$

Marqasi in Gurgum hat sich Salmanassar III. bereits 858 unterworfen $^{67}$ und war danach nie mehr Ziel eines seiner Feldzüge. Obwohl es sich im 8. Jahrhundert zwei antiassyrischen Koalitionen anschloss, gelang es seinen Königen trotzdem, noch bis ins Jahr $711 \mathrm{zu}$ überleben. ${ }^{68}$

Die in Tabāl, und damit bereits außerhalb des syrischen Raumes gelegene Königsstadt Artulu ist 836 von den Assyrern umzingelt, aber nicht eingenommen worden, was für Kategorie 3 spricht. Angesichts der weiten Ausdehnung des Feldzuges erscheint es jedoch fraglich, dass Salmanassar die Belagerung von Artulu ernsthaft und mit dem Ziel der tatsächlichen Eroberung betrieben haben sollte. Oben wurde bereits die Vermutung geäußert, dass es ihm hier wohl wieder einmal nur um die Erpressung von Geschenken ging. ${ }^{69}$

Unklar ist auch die Zuordnung von Kummuhi. Da es spätestens seit 866, also schon vor der Zeit Salmanassars III., zu den Vasallen Assyriens gehörte $^{70}$ und in diesem Zustand verblieb, wurde das Verteidigungspotential dieser Stadt bis zu ihrer Annexion durch Sargon II. im Jahre $708^{71}$ nie auf die Probe gestellt.

Wer den Wert der Befestigungsanlagen einer Stadt quantifizieren möchte, kann ihn nach der Zeitspanne bemessen, über die hinweg sie ihrer Stadt das Überleben im Angesicht eines aggressiven und übermächtigen Gegners ermöglichten. Nehmen wir zum Beispiel die drei Zentren Karkemiš, Arpad und Damaskus, so lässt sich das Jahr 856 als Beginn der Bedrohungssituation bestimmen, denn seit diesem Jahr besaß Assy-

66 Yamada $(2000,221-224)$.

67 Yamada $(2000,78 \mathrm{G})$.

68 Hawkins $(2000,249-252)$.

69 Yamada (2000, 209-214).

70 Grayson (1991, 219 iii 95-96) bietet den frühesten Beleg einer Tributzahlung aus Kummuhi.

71 Fuchs (1994, 443f.) mit Fuchs (1998, 83). 
rien mit Til-Barsip einen Stützpunkt in unmittelbarer Nähe zumindest der beiden erstgenannten Städte. Rechnen wir bis zu ihrem jeweiligen Fall, so beträgt der Wert für Arpad (eingenommen 741) 115 Jahre, für Damaskus (eingenommen 732) 124 Jahre und für Karkemiš (eingenommen 717), obgleich es von den drei Städten dem assyrischen Til-Barsip am nächsten lag, sogar 139 Jahre. Verbanden sich die Befestigungswerke mit dem Vorzug unzugänglicher Lage, so konnte dies, wie im Falle der schon erwähnten Inseln Tyros und Arwad, den Wert ins Unendliche, nämlich bis zur Uneinnehmbarkeit steigern. Wenn sich also die assyrischen Herrscher so mancher Stadt gegenüber kompromissbereit zeigten, so deshalb, weil sie sehr wohl wussten, dass sie sich an ihnen und ihren Befestigungen die Zähne würden ausgebissen haben.

Angesichts solcher Wirksamkeit der Befestigungsanlagen vor allem großer Städte stellt sich die Frage, wie es möglich war, dass in den letzten Jahrzehnten des 8. Jahrhunderts dann all diese scheinbar so unbezwinglichen Bollwerke in rascher Folge von den Assyrern erobert werden konnten.

Von den Tagen Salmanassars III. bis in die dreißiger Jahre des 8. Jahrhunderts schien sich hinsichtlich der assyrischen Möglichkeiten zunächst nicht viel geändert zu haben. Tiglatpileser III. benötigte zur vollständigen Eroberung des Reiches Bît-Agūsi mitsamt seiner Hauptstadt Arpad, die 741 fiel, insgesamt vier Jahre (743-740), für die Einnahme von Damaskus zwei Jahre (733-732). ${ }^{72}$ Aber bereits die im Jahre 738 erfolgte Einnahme von Kinalia und damit die Aufhebung des Reiches Unqi bzw. Pattin, gestaltete sich erstaunlich einfach, ganz so, als habe man den abtrünnigen König und seine Schätze nur eben im Vorüberziehen mitnehmen müssen..$^{73}$

Das Tempo der assyrischen Übernahmen beschleunigte sich in den zwanziger Jahren, denn entsprechend dem Gebietsstand, den die Inschriften Sargons II. als gegeben voraussetzen, müssen in den Jahren von 728 bis 722 Sam'al, Adana in Que und auch die Stadt Hamat gefallen sein, ${ }^{74}$ während sich die Eroberung von Samaria einigermaßen sicher auf das Jahr 722 datieren lässt. ${ }^{75}$

72 Siehe wiederum Tadmor (1994, 232-235) bzw. Millard (1994, 43 ff.).

73 In den erhaltenen Teilen des Annalenberichtes ist von Kampfhandlungen keine Rede, und es wäre in den Lücken des Textes auch kein Platz für entsprechende Beschreibungen, siehe Tadmor (1994, 56 ff.: Ann.25: 3'-12').

${ }^{74}$ Kein assyrischer König würde es unterlassen haben, sich der Annexion so wichtiger Städte gebührend zu rühmen, sofern er sie erobert hätte. Da sich in den Inschriften Sargons II. und Sanheribs keinerlei Hinweis dieser Art findet, müssen sich die drei Städte bereits im Besitz dieser beiden Könige befunden haben. Sargon II. führt Sam'al 
Mit einer Mühelosigkeit, die anderthalb Jahrhunderte zuvor, zur Zeit Salmanassars III., unvorstellbar gewesen war, gelang es dann Sargon II. in nur drei militärischen Spaziergängen, 717 Karkemiš, 711 Melidu, Til-Garimmu und Marqasi in Gurgum, so wie 708 Kummuhi zu annektieren. ${ }^{76}$ Als Feldzüge mag man diese Unternehmungen kaum mehr bezeichnen, denn es ist dabei zu keinerlei Kampfhandlungen oder gar Belagerungen gekommen. Bei der Einnahme von Kummuhi befand Sargon es nicht einmal mehr für nötig, noch persönlich anwesend zu sein. Er hat diese fünf Städte eher kassiert als erobert, denn sie fielen ihm wie überreife Früchte in den Schoß. Fünf Mal wiederholt sich hier derselbe Vorgang, den schon die Inschriften Tiglatpilesers III. im Bericht von der Einnahme der Stadt Kinalia (738) skizzieren: Assyrische Truppen erscheinen vor der Stadt, verhaften den Herrscher und führen ihn ab. Seine Untertanen werden zu Assyrern, sein Besitz wandert in die Schatzkammern von Kalhu bzw. Dūr-Šarrukīn, seine Armee wird den assyrischen Streitkräften einverleibt, sein Territorium wird zur assyrischen Provinz.

Was ist da geschehen? Eine neue, wirkungsvollere Belagerungstechnik haben die Assyrer nicht erfunden, denn wie Sanherib vor Jerusalem (701) und Asarhaddon vor Melidu (675) erfahren musste, konnten Belagerungen noch immer ganz genau so frustrierend enden, wie weiland zu Zeiten

(Samalla) zusammen mit Hammatu und Dimašqu auf, die sich zu seiner Zeit definitiv unter direkter assyrischer Herrschaft befanden (Fuchs 1998, 43: VI.e, 3-5), und er behandelt Que als sein selbstverständliches Eigentum, das er gegen fremden Zugriff schützt, und dessen Gebiet seinem Statthalter als Ausgangspunkt für Feldzüge gegen Mitā von Mušku dient (Fuchs 1994, 455). Der Aufstand des Jaubi'di und Ilubi'di von Amattu (Hamat) sorgte für Unruhen in den Provinzzentren Arpad, Simirra, Damaskus und Samaria und fand seinen Mittelpunkt in Qarqar, das zum Gebiet von Hamat gehörte. Da die Stadt Hamat in diesem Zusammenhang keine Erwähnung findet (Fuchs 1994, 200f. Prunk.33-36), ist sie selbst wohl von den Umtrieben des Jaubi'di verschont geblieben. Sie muss folglich schon vorher erobert worden sein und wurde offenbar von einem assyrischen Statthalter regiert, der es verstand, den Aufstand von seiner Stadt fernzuhalten. Als mögliche Zeitspanne für die Eroberung von Sam'al, Que und Hamat kommen nur die beiden letzten Jahre Tiglatpilesers III. $(728,727)$ und die kurze Regierungszeit Salmanassars V. (726-722) in Betracht, denn nur für diesen Zeitraum sind keine Inschriften verfügbar und auch in den Eponymenchroniken sind die Namen der in diesen Jahren bekämpften Feinde nicht erhalten geblieben (Millard 1994, 45 f.). Gegen Radner $(2006,66)$ sub Hamattu kann der nach 738 noch verbliebene Rest von Hamat nicht schon 732 erobert worden sein, da dessen König Eni-ilu noch in einer 729 entstandenen Inschrift als Tributzahler aufgelistet wird (Tadmor 1994, Summ.7 r.8').

75 Fuchs $(1994,457)$ und Fuchs $(1998,84$ f.).

76 Siehe Fuchs (1994, 435 ff. sub Gargamiš, Kummuhi, Marqasi, Meliddu und Til-Garimmu). Zu Meliddu und Til-Garimmu siehe auch Fuchs (1998, 48: VII.e). 
Salmanassars III., sofern sich die Bewohner der belagerten Stadt wehrten. Aber genau dazu war in den großen syrischen Zentren gegen Ende des 8. Jahrhunderts die Bevölkerung immer weniger bereit.

An der bloßen äußeren Bedrohung durch die assyrische Macht kann es nicht gelegen haben, denn diese war schon um die Mitte des 9. Jahrhunderts furchterregend gewesen, nach den Ursachen muss vielmehr im Innern der Königreiche gesucht werden. Hierbei fällt auf, dass sich stets gerade jene Reiche widerstandslos ergaben, deren Könige noch kurz zuvor willfährige assyrische Vasallen gewesen waren, während sich renitentere Gebilde wie Bìt-Agūsi und Damaskus auch weiterhin nur unter groBen Anstrengungen erobern ließen. Die fragliche Schwäche kann damit nur durch das Vasallenverhältnis zu Assyrien verursacht worden sein, wobei es eines gewissen Vorlaufes bedurfte, bis es den Widerstandswillen seiner Opfer zu lähmen begann: In Unqi/Pattin, das vor seinem Fall im Jahre 738 ein zuverlässiger Vasall Tiglatpilesers gewesen war, hatte die Wirkung bereits eingesetzt. Demgegenüber waren die Reiche Melidu und Gurgum, deren Herrscher noch 743 gemeinsam mit Bit-Agūsi und Urarț gegen Tiglatpileser gefochten hatten, erst zur Zeit Sargons II. reif, gepflückt zu werden.

Es wäre allerdings voreilig, daraus eine Art allgemeine Inkubationszeit von etwa ein bis drei Jahrzehnten ableiten zu wollen und das Fortschreiten innerer Schwäche als unabwendbares Schicksal grundsätzlich aller assyrischer Vasallen zu betrachten. Im Königreich Kummuhi, das mehr als anderthalb Jahrhunderte lang (ca. 866-708) assyrischer Vasall war, stellte sich die Lähmung erst ganz am Ende dieses langen Zeitraumes ein, etwa zur gleichen Zeit, als sie auch diejenigen seiner Nachbarn befiel, die sich sehr viel kürzer in assyrischer Abhängigkeit befunden hatten. Der fragliche Effekt trat also grundsätzlich erst während der zweiten Hälfte des 8. Jahrhunderts ein, nachdem die assyrischen Könige die Kontrolle über Syrien schon weitgehend erlangt hatten.

Die assyrische Vasallität wirkte sich auch keineswegs in allen Reichsteilen schädlich aus. So hat sie in der südlichsten Peripherie des syrischen Raumes zu keiner inneren Schwächung der dortigen Reiche geführt.77 Das Königreich Juda hat noch 701 gegen Sanherib erbitterten Widerstand geleistet und die kleinen Reiche Ammon, Moab und Edom haben mit Assyrien erfolgreich koexistiert. In diesem Gebiet aber hat sich die assyrische Macht nie in demselben Maße etablieren können wie weiter

Eine mögliche Ausnahme stellt Ašdod dar, das zur Zeit Sargon heftige innere Unruhen erlebte (s.u.). 
im Norden, denn schon wegen der Nähe Ägyptens, dessen Herrscher die assyrische Macht offen oder insgeheim zu schwächen trachteten, mussten hier die Verhältnisse unsicherer bleiben. Das Phänomen innerer Schwächung der Vasallenreiche setzte nur dort ein, wo sich Assyrien so vollständig durchgesetzt hatte, dass es seinen Vasallen dauerhaften Frieden und zuverlässigen Schutz nach innen und außen garantieren konnte, während ihnen gleichzeitig jegliche Möglichkeit unabhängiger Außenpolitik genommen war.

Die betroffenen Vasallenkönige waren damit ganz auf ihr eigenes Gebiet verwiesen, durften aber zumindest innerhalb desselben auch weiterhin frei schalten und walten, denn der assyrische Oberherr mischte sich in die internen Angelegenheiten der Vasallenreiche nicht ein. Aus Sicht des assyrischen Königs bestand der Vorteil indirekter Herrschaft ja gerade und vor allem darin, dass er Zahlungen und Dienstleistungen aus den unterworfenen Gebieten bezog, ohne sich selbst dort engagieren zu müssen. Da aber für die Untertanen eines Vasallenkönigs keine Möglichkeit vorgesehen war, am assyrischen Hof Klage gegen ihren Herrn wegen Misswirtschaft erheben zu können, stellte Assyrien somit jedem seiner Vasallen gleichsam einen Freibrief zur hemmungslosen Unterdrückung und Ausplünderung seiner Untertanen aus.

Durch die assyrische Oberherrschaft verschoben sich die Machtverhältnisse innerhalb eines Vasallenreiches sehr einseitig zugunsten des örtlichen Herrschers, dessen Stellung gegenüber seinen Untertanen nun ungleich stärker war als je zuvor. Für ihn schien es kaum mehr notwendig, noch Zeit und Mühe darauf zu verwenden, mit den eigenen Leuten zum Kompromiss oder gütlichen Ausgleich zu gelangen, konnte man ihnen doch mit der assyrischen Macht im Rücken die eigenen Wünsche ganz einfach diktieren! Man war jetzt auch viel weniger auf ihre Unterstützung und Loyalität angewiesen, denn der Schutz, den der mächtige assyrische Oberherr gewährte, schreckte jeden möglichen Angreifer doch viel wirkungsvoller ab, als es jedes eigene Aufgebot vermocht hätte. Revolten und Umsturzversuche schien man gleichfalls kaum mehr fürchten zu müssen, garantierte doch Assyrien den Fortbestand von Herrschaft und Dynastie. War also der assyrische Herrscher seinem Vasallen wohlgesonnen, so konnte dieser die Bewohner seiner Stadt zu bloßen Ausbeutungsobjekten degradieren.

Die Sichtweise eines assyrischen Vasallenkönigs zeigt sich nirgends besser als in den Inschriften aus Sam'al. Da stellt König Barrākib sich selbst und seinen Vater Panamuwa II. vor allem als treue Diener ihres Herrn, des Assyrerkönigs Tiglatpileser III. heraus, von dem sie mittlerweile ganz und gar abhingen: Panamuwa II. erkauft mit Geschenken die Hilfe des 
Assyrerkönigs (S172), ${ }^{78}$ dessen Gewandsaum er demütig ergreift (S190). Er läuft „am Rad (des Streitwagens) seines Herrn Tiglatpileser, des Königs von Assyrien" und beteiligt sich mit großem Eifer an dessen Feldzügen und Deportationen (S195-198). Am Ende findet seine Karriere vollendeter sklavischer Unterwürfigkeit ihren krönenden Abschluss damit, dass er während eines Feldzuges gegen Damaskus ganz und gar standesgemäß „zu Füßen seines Herrn Tiglatpileser" stirbt, heftig beweint von diesem und von den Mit-Vasallen (S201-205). Barrākib führt diese Beziehung nach Kräften fort. Auch er ist ein Diener des Tiglatpileser (S222) und läuft am Rad (des Streitwagens) seines Herrn (S225), seine Loyalität erstreckt sich nicht nur auf diesen selbst, sondern auch auf dessen Würdenträger, wobei er in seiner Devotion alle übrigen Vasallen übertrifft, und er hat auch schon seine Söhne in diesem Sinne erzogen (S235-238).

Es besteht auch keine Unklarheit darüber, wem die Könige von Sam'al den Thron verdanken: Panamuwa II. wird gegen eine entsprechende Zahlung von Tiglatpileser eingesetzt, wobei die Ausrottung missliebiger Angehöriger der Dynastie offenbar im Preis inbegriffen ist (S172-174). Barrākib verdankt die Herrschaft dem Gott Rākib-El und seinem Herrn Tiglatpileser (S223), aber die unablässige Beteuerung seiner Loyalität dem Letzteren gegenüber zeigt unmissverständlich, wer als der wichtigere von beiden zu gelten hat.

Dem eifrigen Vasallen wird für seine Selbstentäußerung reicher Lohn zuteil, denn Tiglatpileser erweitert das Territorium von Sam'al auf Kosten weniger devoter Nachbarkönige (S199). Und die eifrig bekundete Untertänigkeit zahlt sich auch materiell aus:

(Und) was meinen (Va)ter (Panamuwa II.) betrifft, so war er wahrlich reich an Silber und auch wahrlich reich an Gold. (S189).

Barrākib sieht sich, wenn er an den Feldzügen seines Herrn teilnimmt, als Mitglied eines exklusiven Clubs steinreicher assyrischer Vasallen:

Und ich lief am Rad (des Streitwagens) meines Herrn, des Königs von Assur, inmitten großer Könige, reich an Silber und reich an Gold. (S225)

Und auch daheim änderte sich jetzt einiges. Hatten die Könige bisher noch mit dem von Kilamuwa erbauten Palast Vorlieb genommen, so gönnt sich Barrākib eine neue Anlage, die so prächtig ist, dass er die Bauten der „großen Könige“, d.h. die der übrigen Mitglieder des illustren Vasallen-Clubs, noch übertreffen soll (S226-233).

\footnotetext{
78 Texthinweise beziehen sich auf Tropper (1993, $153 \mathrm{ff}$.).
} 
In den Inschriften des Kilamuwa, der ein Jahrhundert früher, im 9. Jahrhundert regiert hatte, als das Vasallenverhältnis zu Assyrien noch nicht gefestigt gewesen war, klingt es noch ganz anders, dort wird die Fürsorge betont, die der Herrscher seinen Untertanen angedeihen lässt. Unter anderem heißt es da:

Und wer (noch) niemals das Gesicht eines Rindes gesehen hatte, den machte ich zum Besitzer einer Rinderherde, und (ebenso) zu einem Besitzer von Silber und einem Besitzer von Gold. (S26-27)

Kilamuwa hat auf seine Leute noch Rücksicht nehmen müssen, denn er war auf sie angewiesen und musste mit ihnen auskommen. Barrākib, dem letzten König von Sam'al, der sein Wohl und Wehe einzig und allein mit der Gunst des Königs von Assyrien verknüpft sieht, genügt es dagegen vollkommen, wenn allein der König von Sam'al, also er selbst, „wahrlich reich an Silber und auch wahrlich reich an Gold“ ist. Die Untertanen spielen für ihn keine Rolle mehr, denn solange Tiglatpileser ihm gewogen ist und seine schützende Hand über ihn hält, haben die Bewohner von Sam'al gar keine andere Wahl als zu gehorchen. Barrākib ist ihnen auch dadurch entfremdet, dass er sich längst an Maßstäben orientiert, die weit jenseits des kleinen Sam'al, am assyrischen Hof gesetzt werden. Dort bewegt er sich im Kreis anderer ,großer Könige, reich an Silber und reich an Gold“, deren Stil er nacheifert und die er mit seinen Palastbauten zu beeindrucken hofft.

Wo aber kam dieser Reichtum her? Von ihrem assyrischen Herrn können Panamuwa II. und Barrākib ihr Silber und Gold jedenfalls nicht bekommen haben, denn als Vasallen waren sie es, die ihrem Herrn Tribut zahlten, nicht umgekehrt. ${ }^{79}$ Allenfalls als Teilnehmer siegreicher assyrischer Feldzüge mögen die Könige von Sam'al an der Beute beteiligt worden sein, jedoch bestenfalls in bescheidenem Umfang, denn die Assyrerkönige waren ihrerseits begeisterte Sammler von Edelmetallen. Panamuwa II. und Barrākib können ihren Reichtum also nur auf dem Wege erbarmungsloserer Besteuerung ihrer Untertanen erworben haben, deren Belastung insgesamt beträchtlich gewesen sein muss: Damit sich Panamuwa II. und dann Barrākib bei Tiglatpileser als dessen untertänige Diener einschmeicheln konnten, mussten die Abgabepflichtigen von Sam'al sowohl für die kleine Armee aufkommen, mit der sich Sam'al an den assyrischen Kriegszügen zu beteiligen hatte, wie auch die Tribute zu-

79 In Assyrien weilende Vasallenfürsten oder Gesandte erhielten durchaus Geschenke in Gestalt von Armreifen, Ringen und Gewändern, jedoch waren diese von eher symbolischem Wert, siehe etwa Fuchs (1998, 29: V.b-d.55-59) bzw. Postgate (1994). 
sammenbringen, die Jahr für Jahr an Assyrien zu entrichten waren. ${ }^{80}$ Die üblichen Leistungen, die der Aufrechterhaltung des Gemeinwesens dienten, wurden weiterhin gefordert und außerdem mussten sie ihre Könige zu Besitzern von viel Silber und Gold machen, und ihnen einen opulenteren Lebensstil ermöglichen als bisher, so etwa durch den Bau neuer, verschwenderisch ausgestatteter Palastanlagen.

Panamuwa II. und mehr noch Barrākib dürften die beiden rücksichtslosesten Blutsauger gewesen sein, die je in Sam'al herrschten, und es verwundert nicht, dass auf Barrākib kein weiterer König mehr folgte. Die Umstände, unter denen Sam'al schließlich zur assyrischen Provinz geworden ist, sind zwar nicht überliefert, aber man darf wohl vermuten, dass der assyrische König, der die Eigenständigkeit von Sam'al schließlich aufhob, sei es nun Tiglatpileser III. oder Salmanassar V. gewesen, bei der Einnahme der Stadt auf ebenso wenig Widerstand stieß wie die Truppen Sargons II. bei der Übernahme von Karkemiš oder Melidu.

Das Vasallenverhältnis zu Assyrien wirkte somit wie ein langsames, schleichendes Gift, das den Vasallen beständig mit dem Angebot lockte, zur Verabsolutierung der eigenen Macht sich dem Assyrerkönig mit Haut und Haaren zu verschreiben. Mochte der eine oder andere Vasall dieser Versuchung noch widerstehen, so würde ihr eben sein Sohn oder sein Enkel erliegen, denn das Angebot selbst blieb allzeit bestehen. Wurde aber der so einfache Weg, den es versprach, erst einmal beschritten, so gab es kein Zurück mehr, und der innere Zusammenhalt, der die Selbstbehauptung einer Stadt ermöglichte, war damit unwiderruflich zerstört.

Nach außen hin mochte dann alles sehr zum Besten stehen, womöglich investierte ein solcher Herrscher einen Teil der zusätzlichen Abgaben, die er seiner Stadt abpressen konnte, sogar in noch gewaltigere Festungswerke, als seine Stadt sie vordem besessen hatte. Aber der äußere Schein trog, denn in Wahrheit war er längst hilfloser als ein kleines Kind. Seine Untertanen werden sich nämlich gefragt haben, wozu sie ihren Herrscher denn überhaupt noch benötigten. Der Assyrerkönig fällte alle außenpolitischen Entscheidungen und schützte die Stadt, wogegen ihr eigener König nur noch vor den Assyrern kroch und, von ihnen gedeckt,

80 Wie die Berechnungen von Yamada (2000, 240-241) zeigen, war die Höhe des Tributes, den Assyrien seinen Vasallen abverlangte, für sich genommen keineswegs so bemessen, dass er den Vasallen ruinieren musste. Diese Zahlungen können nur dadurch zum Problem geworden sein, dass die Vasallenkönige ihre eigenen Ausgaben nicht einschränkten und die assyrischen Forderungen in vollem Umfang nach unten weiterreichten, so dass die Abgabepflichtigen diese Last zu allem übrigen noch zusätzlich zu tragen hatten. 
in einer Weise despotisch auftrat, wie er sich das nie hätte erlauben können, wäre er auf sich allein gestellt gewesen. Alle Vorteile seiner Beziehung zu Assyrien genoss allein er, während alle Belastungen, die sie nach sich zog, ungeschmälert nach unten abgewälzt wurden. In den Augen ihrer Untertanen müssen solche Vasallenkönige mehr und mehr das Dasein nutzloser Drohnen oder gar vollgefressener Parasiten geführt haben.

Die teils heftigen Unruhen, die in dieser Zeit innerhalb mancher assyrischer Vasallenkönigreiche ausbrachen ${ }^{81}$ und bis zur Vertreibung loyaler assyrischer Vasallen durch ihre Untertanen führen konnten, ${ }^{82}$ mögen unterschiedliche Ursachen gehabt haben, sind aber wahrscheinlich auch als Reaktionen auf die gewachsenen Spannungen zwischen den lokalen Herrschern und ihren zunehmend entfremdeten Untertanen zu sehen.

Selbst die stärksten Mauern und die volkreichste Stadt konnten ihre Wirkung nur dann entfalten, wenn die Bewohner dazu bereit waren, sie zu verteidigen und die damit verbundenen Härten auf sich zu nehmen. Das aber setzte gerade jenes Einvernehmen und jenes soziale Vertrauen voraus, das die Vasallenkönige unwiderruflich verspielten, wenn sie sich der Macht ihres Oberherrn allzu rücksichtslos bedienten. Ihr Schicksal hing nun an einem seidenen Faden, der mit der Laune des Assyrerkönigs identisch war. Überwarf sich der Vasall mit seinem Herrn, so war er ver-

81 So fand auf dem Gebiet des Königreiches Hamat unter Führung des Azrijau ein Aufstand statt, der weite Teile dieses Territoriums erfasste und von den Assyrern 738 niedergeschlagen wurde (Tadmor 1994, 58 ff.: Ann.19* 1-11). Gegen Lipiński (2000, 314) war Azrijau nicht der damalige König von Hamat. Der dort zitierte Nebensatz s̆a ina hitți gullulte ana Azrijau ékimü handelt von den Aufständischen und ist zu übersetzen: (jene Gebiete) „die sie auf verbrecherische und widerrechtliche Weise für Azrijau geraubt hatten" (Tadmor 1994, 63: Ann.19*: 10 bzw. 89: Ann.26: 7). Der auf diese Weise geschädigte König von Hamat war der für dasselbe Jahr bezeugte Enī-ilu (Tadmor 1994, 68: Ann.13*: 11f.). Dasselbe Phänomen, dass ein Text einen Rebellen namentlich nennt, die Aufständischen dann aber in der Mehrzahl agieren lässt, findet sich in ganz derselben Weise in einer Inschrift Sargons II. bei der Beschreibung des 711 in Ašdod niedergeschlagenen Aufstandes (Fuchs 1998, 74 Anm. 105).

82 Als loyale assyrische Vasallen, die von ihren eigenen Leuten vertrieben wurden, sind zu nennen Kibaba von Harhar (Fuchs 1994, 103: Ann.96) und Ahimeti von Ašdod (Fuchs 1998, 44 ff.: VII.b,1-14). Wenn diese beiden Fürsten nach der Niederschlagung der gegen sie gerichteten Aufstände nicht wieder in ihre Herrschaft eingesetzt wurden, so wohl deshalb, weil den Assyrerkönigen nur an solchen Vasallen gelegen war, die innerhalb ihrer Reiche für Ruhe sorgen konnten, wodurch sie den Oberherrn entlasteten und zur Erhaltung des Reiches beitrugen. Versprach der Vasall dies zu leisten, so wurde er gegen auswärtige Feinde oder dynastische Rivalen unterstützt. Vasallenkönige aber, die sich gegen ihre Untertanen nur mit fremder Hilfe behaupten konnten, ernteten Spott und Verachtung (Fuchs 1998, $117 \mathrm{f}$.), und wer gar vor dem eigenen Volk davonlief, bewies damit seine Unfähigkeit zu herrschen und erhielt keine zweite Chance. 
loren, und erschienen dann assyrische Truppen vor seiner Stadt, so hatte ein solcher Herrscher von seinen Untertanen womöglich noch mehr zu fürchten als von den Assyrern selbst.

Hinzu kam, dass die Assyrerkönige ihrerseits den Verteidigungswillen der Untertanen feindlicher Herrscher zu vermindern suchten, indem sie ihnen für den Fall der Unterwerfung erträgliche Bedingungen in Aussicht stellten. Ihren Inschriften zufolge waren sie bemüht, bei der Einverleibung eines neuen Territoriums an den Lebensverhältnissen der Bewohner möglichst wenig zu verändern. Selbst im Falle der Deportation versprachen sie, den davon Betroffenen am zugewiesenen Wohnort gleichwertige oder gar bessere Verhältnisse zu bieten. ${ }^{83}$ Die neu hinzugewonnene Bevölkerung sollte darüberhinaus nicht über Gebühr belastet werden, sondern hatte fortan dieselben Abgaben zu zahlen und dieselben Dienste zu leisten wie die Assyrer selbst. Auch wenn sich nicht mehr entscheiden lässt, in welchem Maße die Inschriften hier lediglich gute Vorsätze wiedergeben, bei denen es dann vielleicht geblieben ist, so wird doch erkennbar, dass nach dem Willen der Assyrerkönige der Übergang unter direkte assyrische Herrschaft den Betroffenen keinen Nachteil bringen sollte. Gerade wenn ein Vasallenkönig unbeliebt war, konnte dies in seinem Volk die Ansicht verbreiten helfen, dass es keinen Unterschied mehr machte, sondern vielleicht sogar von Vorteil sein werde, wenn der eigene ungeliebte Herr durch einen assyrischen Statthalter ersetzt wurde.

Ein anschauliches Beispiel für das Wirken des Zersetzungsprozesses, den die assyrische Vasallität unter den geschilderten Voraussetzungen entfaltete, bietet die Geschichte des Königreiches Melidu. Während des 9. und 8. Jahrhunderts waren ab und an assyrische und dann auch urarțäische Könige vor der gleichnamigen Hauptstadt Melidu aufgetaucht und hatten sich damit begnügen müssen, Verträge abzuschließen und reich beschenkt von dannen zu ziehen. Erobert wurde die Stadt jedoch nicht.

Nach dem Sieg aber, den Tiglatpileser III. im Jahre 743 bei Kištan und Halpi gegen die Urarțäer erfocht, gerieten die Könige von Melidu endgültig in die Abhängigkeit zu Assyrien. ${ }^{84}$

Als sich dann im Jahre 711 der damalige König Tarḩunazi den Zorn Sargons II. zuzog, befand er sich in einer aussichtslosen Lage. Das Vasallenverhältnis hatte seine Wirkung drei Jahrzehnte lang entfalten können, und Tarhunazi war bei seinen Untertanen weit verhasster, als er selber ahnte. Zwar war er sich durchaus im Klaren darüber, dass er es unter

\footnotetext{
83 So der rab šaqê in seiner Rede an die Einwohner Jerusalems (2. Könige 18,31-32).

84 Tadmor (1994, 100 St.I B $21^{\prime}$ ff. und 232f.).
} 
allen Umständen vermeiden musste, zusammen mit seinen Untertanen in seiner Hauptstadt eingesperrt zu werden, und wich deshalb nach TilGarimmu aus, der anderen großen Festung, die er besaß. Wie sich zeigte, mochten sie ihn dort aber genauso wenig leiden, denn als die Assyrer nach der kampflosen Einnahme von Melidu schließlich auch vor Til-Garimmu erschienen, öffneten ihnen die Bewohner sogleich die Tore und lieferten den unbeliebten Tarhunazi mitsamt seinen Anhängern gefesselt aus. ${ }^{85}$ Für die Assyrer gestaltete sich der Feldzug so zum Spaziergang, sie konnten im selben Jahr auch noch das benachbarte Marqasi einnehmen, dessen König Tarhulara soeben von seinem Sohn Muttallu umgebracht worden war. ${ }^{86}$ Auch in Marqasi stießen die assyrischen Truppen auf keinerlei Widerstand. Damit hatte das assyrische Heer in nur einem einzigen Jahr und praktisch im Vorübergehen drei große Festungsstädte einnehmen können, zu deren Eroberung nur wenige Jahrzehnte zuvor noch in jedem einzelnen Falle jahrelange Anstrengungen erforderlich gewesen wären. Möglich war all das nur, weil die Einwohner jener drei Städte nicht bereit waren, für ihre abgewirtschafteten Könige einen Krieg mit Assyrien auf sich zu nehmen.

In ähnlicher Weise war bereits 717 Karkemiš an Assyrien gefallen. Die Bewohner von Karkemiš hatten das nahegelegene assyrische Provinzzentrum Til-Barsip unmittelbar vor Augen gehabt, und es mag ihnen je länger desto fraglicher erschienen sein, worin sich ihre Lage von derjenigen der assyrischen Untertanen in Til-Barsip überhaupt noch unterschied und welchen Vorteil ihnen die teilweise Eigenständigkeit ihrer Stadt denn eigentlich noch brachte.

Dass es zumindest im Falle von Melidu tatsächlich die Feindschaft der Bewohner gegen ihren König war, die den Assyrern die Stadt in die Hände spielte, und nicht etwa ein wie immer gearteter Fortschritt der assyrischen Belagerungstechnik, erweist das weitere Schicksal dieser Stadt. Wohl kurz vor 675 wurde Melidu den Assyrern wieder entrissen, durch einen Herrscher mit Namen Mugallu. Wer immer er auch gewesen und woher er auch gekommen sein mag, so hat er es jedenfalls verstanden, die Bewohner von Melidu für sich zu gewinnen. Für ihn waren sie bereit,

Fuchs (1994, 125-127: Ann.204-213).

86 Fuchs (1994, 131f.: Ann.234-241). Die Angaben über die Reihenfolge der beiden Eroberungen sind widersprüchlich. In den Annalen des Jahres 711 wird zunächst über Marqasi/Gurgum und dann erst über Kammanu/Meliddu berichtet (Fuchs, 1998, $47 \mathrm{ff.:}$ VII.c-VIII.b), in den Khorsabad-Annalen in umgekehrter Reihenfolge (Fuchs 1994, 204ff.: Ann.204-214). Zu den Hintergründen dieses Problems siehe Fuchs (1998, 87). 
das zu tun, was sie dem verhassten Tarhunazi verweigert hatten, nämlich zu kämpfen. Und so zeigten, als Asarhaddon 675 die Stadt belagern ließ, deren Befestigungsanlagen wieder ihre volle Wirksamkeit: Die Belagerung endete als Fehlschlag und wurde nie wiederholt. ${ }^{87}$

Die Erfolgsformel für das zähe Überleben der syrischen Kleinkönigreiche zwischen 856 und 743 lautete somit:

Befestigungsanlagen + hohe Einwohnerzahl + sozialer Zusammenhalt.

Wo alle drei Faktoren gegeben waren, taten sich die Assyrer sehr viel schwerer mit der Eroberung einer Stadt, als es gemeinhin angenommen wird. In Verbindung mit den beiden anderen Faktoren, der Anzahl der Einwohner und dem gegenseitigen Vertrauensverhältnis, gestatteten die Befestigungsanlagen über viele Generationen hinweg Lebensweisen und Gesellschaftsformen das Überleben, die ohne ihren Schutz der assyrischen Expansion sehr viel früher zum Opfer gefallen wären als es dann tatsächlich der Fall war. Assyrien war im syrischen Raum bereits um die Mitte des 9. Jahrhunderts übermächtig und selbst Koalitionen wie die von Damaskus angeführte vermochten es bestenfalls noch zu behindern, aber nicht mehr zu besiegen. Wenn es dennoch fast anderthalb Jahrhunderte dauerte, bis sich dieses Gebiet endgültig im Besitz der Assyrer befand, ${ }^{88}$ so lässt sich diese enorme Verzögerung vor allem anderen damit erklären, dass sich die vielen Kleinkönige derart fest verschanzt hatten, dass sich die Einnahme auch nur eines einzigen ihrer Zentren so unendlich schwierig, verlustreich und frustrierend gestaltete.

Die syrischen Zentren fielen nicht deshalb, weil die Assyrer neue Waffen oder Methoden ersonnen hätten, ${ }^{89}$ sondern weil die Könige dieser Städte als assyrische Vasallen ihren Untertanen gegenüber in zunehmend

87 Die Belagerung von Melidu blieb deshalb in den Inschriften Asarhaddons unerwähnt. Siehe Grayson (1975, 83 iv 10 und 126: 15).

88 Dies war erst mit der Eroberung von Kummuhi im Jahre 708 der Fall.

89 Die im 7. Jahrhundert angewandten Belagerungsmittel, die in den Anfragen an den Sonnengott aufgeführt sind, unterscheiden sich nicht von jenen, die spätestens seit der altbabylonischen Epoche gebräuchlich waren (siehe dazu Stol 2004, 669). Während jenes langen Zeitraumes, der die altbabylonische von der neuassyrischen Epoche trennt, sind dem Arsenal der Belagerer offensichtlich keine grundlegend neuen Techniken zur Überwindung oder Zerstörung von Befestigungsanlagen hinzugefügt worden. Als neuer, bis dahin nicht dagewesener Faktor kann um die Mitte des 8. Jahrhunderts höchstens der beträchtlich gesteigerte Umfang des assyrischen Heeres gelten, der es erleichtert haben wird, Belagerungsdämme zu errichten, größere Siedlungen vollständig abzuriegeln und Entsatzversuche von außen zu vereiteln (Fuchs 2002, 596f.). 
unerträglicher Weise aufzutreten begannen und damit jeglichen Rückhalt bei der Bevölkerung ihrer Städte einbüßten. ${ }^{90}$ Dort hingegen, wo der innere Zusammenhalt noch immer gegeben war, wie etwa in Jerusalem bei der Belagerung durch Sanherib im Jahre 701, oder dort, wo er wiederhergestellt wurde, wie in Melidu durch den Herrscher Mugallu, richteten die Sargoniden nicht mehr aus als Salmanassar III. anderthalb Jahrhunderte zuvor.

\section{Anhang 1: Die in den Anfragen an den Gott Šamaš erwähnten Arten, eine befestigte Siedlung einzunehmen}

Die Angaben beziehen sich auf Starr (1990). Nur im Falle von ina aramme und ina šubî wurden Belege berücksichtigt, die in der Ausgabe von Starr auf ergänzten Textstellen beruhen.

1. Mühelose Einnahme wegen mangelhafter Vorbereitung des Verteidigers:

- ina šẹtūti 102:7'

- ina mékûti 29:2', 30:7, 102:7'.

- ina mékûti ša șābē sa libbi āli 30:7-8(?), 31:8.

2. Verhandlungen und ihre Resultate:

- ina pî țābi u salìm tubbāti 30:6, 43:9, 44:10, 63:7-8, 102:3'.

- ina dibbì tạăuti (...) 101:5'-6'

90 Das erinnert an eine Textstelle im zwanzigsten Kapitel von Machiavellis Fürst, wo es heißt: „Die beste Festung, die es gibt, ist, beim Volk nicht verhasst zu sein. Wenn du auch Festungen besitzest, aber beim Volk verhasst bist, so retten sie dich nicht; denn hat ein Volk einmal die Waffen ergriffen, so findet es immer eine fremde Macht, die ihm hilft.“ Dieser Satz trifft zwar dem Wortlaut, jedoch nicht dem Sinn nach die hier geschilderte Situation der assyrischen Vasallen. Machiavelli meint mit Festungen an dieser Stelle nämlich nicht Stadtbefestigungen zum Schutz gegen äußere Feinde, sondern Zwingburgen, die dazu erbaut sind, den Herrscher vor dem eigenen Volk zu schützen. Dies geht aus folgender Bemerkung im gleichen Kapitel hervor, die dem Zitat vorangeht: „Der Herrscher, der mehr Angst vor seinem Volk als vor fremden Mächten hat, soll Festungen bauen; wer aber auswärtige Mächte mehr fürchtet als sein Volk, soll es unterlassen." Anschauliche Beispiele seiner eigenen Zeit lassen Machiavelli am Ende des Kapitels folgendes Resümee ziehen: „Wenn man dies alles in Betracht zieht, so lobe ich den, der Festungen baut, geradeso wie den, der keine baut; ich tadle aber jeden, der im Vertrauen auf Festungen den Hass des Volkes gering achtet." (Zitate nach Zorn 1972, 91 f.) Grundlage der Selbstbehauptung ist auch für Machiavelli das Einvernehmen zwischen Herrscher und Volk, denn, wie es im 10. Kapitel ausdrücklich heißt: „die Menschen sind immer Gegner von Unternehmungen, bei denen Schwierigkeiten zu erwarten sind; und ein Angriff gegen einen Herrscher, der seine Stadt wohl befestigt hat und beim Volk nicht verhasst ist, ist nie eine leichte Sache." (Zorn 1972, 44) 
- ina adê zakār šum ili u ištari 43:9.

- ina puluhti 29:5'.

- ina si ûti 43:6, 44:8, 102:7'.

- ina sīhi u bārti 63:8.

3. List:

- ina mimma šipir(ti) nikilti ša șabāt āli mal bašû 29:6'-7', 30:10-11, 43:10, 44:11, 63:9, 102:8'. 43:10 bietet sipirti nikilti, hier ist also an eine listig abgefasste Botschaft, nicht an ein listiges Werk (sipir nikilti) gedacht.

4. Waffengewalt:

- ina danāni 43:6, 63:6, 102:6'.

- ina epēš kakki qabli u tāhăazi 30:5-6, 31:6-7, 43:7, 44:8, 63:5, 102:3'.

- ina niksi (ina) pilši 31:7, 43:7, 44:9 (nur ina pilši), 63:6, 102:4'.

- ina simmilti 30:8 (ina simmilat dūrī), 43:7 (ina simmilti u nabalkatti), 44:9, 101:7' (ina gišs simmilāti (I.DIB).MEŠ), 102:4'.

- ina aramme 29:3', 43:8, (44:9), (63:7), 101:6', 102:4'.

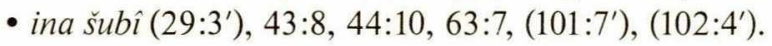

- ina kakki danni 102:5'.

- ina mê mahāhi 102:5.

- ina lulìmiti 30:9.

5. Aushungern:

- ina bubūti 30:7, 43:8, 44:9.

- ina sunqi hušahhi u bubüti 29:3'-4'.

- ina șummê 102:6'.

\section{Anhang 2: niksu und pilšu.}

Die Begriffe niksu und pilšu sind offenbar Synonyme, jedenfalls wird das Ergebnis jener Einbruchsmethode, bei der sich die Einbrecher dadurch Zutritt in ein Privathaus verschaffen, dass sie die Hauswand durchbrechen, in $\S 21$ des Kodex Hammurabi mit pilšum, in einer neubabylonischen Rechtsurkunde ${ }^{91}$ mit niksu bezeichnet. Der Täter "schneidet“ (nakāsu) oder „bohrt“ (palāsu) sich also durch die Ziegelwände hindurch.

Die beiden Bezeichnungen sind derart allgemein gehalten, dass sie, wenn sie im Kontext von Belagerungen gebracht werden, von sich aus nicht erkennen lassen, welche Art Loch oder Bresche jeweils konkret vorliegt, ob also rasch improvisierte Mauerdurchbrüche vergleichbar den erwähnten Einbruchszenarien gemeint sind, oder ob es sich um auf-

91 Ebeling (1952-1953, 68: 7-9). 
wändig angelegte Tunnel, Minen bzw. Stollen handelt. Assyrische Reliefabbildungen zeigen beides, ein Relief Assurnasirpals II. sogar beides in ein und derselben Szene. ${ }^{92}$ Soldaten, die sich in Belagerungsszenen am Fuß von Festungsmauern mit Werkzeug zu schaffen machen, ${ }^{93}$ sind aber bei weitem häufiger abgebildet als Tunnel.

Es sind wenigstens zwei Fälle belegt, in denen niksu und pilšu nicht von einem Belagerer, sondern zu unterschiedlichen Zwecken von den Bewohnern einer Stadt angelegt worden sind. In einem Fall versprechen Bewohner der babylonischen Festung Darāti, ihre Stadt den Assyrern durch Verrat in die Hände zu spielen: ${ }^{94}$

Durch Mauerdurchbrüche (niksāni) werden wir Sā'eru und alle Männer, die auf seiner Seite sind, in die Stadt hineinbringen. (So) werden wir Darāti übernehmen und an Marduk-šarru-ușur übergeben! Man soll Bauarbeiten an (mehreren) Häusern vornehmen: In einem Haus, das sich für (unser) Vorhaben eignet, werden wir drinnen einen Mauerdurchbruch anlegen (niksu ina libbi nikkisi). Durch diesen werden wir die Männer hereinbringen. (Am besten) sollte man die Bauarbeiten (in den Häusern) des Erïba und des Sîn-dūru-uṣur vornehmen. Sobald dann einer von ihnen ${ }^{95}$ wie verabredet Darāti betreten hat, werden wir daraufhin die (übrigen) Männer durch die Mauerdurchbrüche (niksāni) hereinbringen. ${ }^{96}$ (So) werden wir die Stadt übernehmen! Einer von ihnen, der sich für (unser) Vorhaben eignet, soll kommen und Darāti betreten. Marduk-šarru-uṣur soll während des dann noch verbleibenden Teiles der Nacht kommen und „das Horn des Atā ${ }^{\star 697}$ umstellen. ${ }^{98}$

Da die Übernahme der Stadt sowohl heimlich bei Nacht als auch in Bälde erfolgen sollte und die kooperationsbereiten Stadtbewohner sicht-

92 Barnett (1975, Tafel 27): Gegen die belagerte Festung werden im Bild jeweils von links und rechts Tunnel vorgetrieben, während man in der Mitte zwei Soldaten damit beschäftigt sieht, Steine oder Ziegel aus der Mauer herauszubrechen.

93 Lediglich angedeutet in Botta (1849, Pl.68 (bis) und Pl.145), mit herabpurzelnden Ziegeln oder Steinen in Barnett (1975, Tafel 177).

94 Marduk-šarru-ușur war wohl der assyrische Befehlshaber, der für die Eroberung jener Region zuständig war, in der Darāti lag. Bei Sā'eru handelt es sich wahrscheinlich um eine bedeutende Persönlichkeit der Stadt Darāti (siehe im selben Brief r.14-17e). Er ist ein Gegner des Marduk-aplu-iddina, dessen Anhänger Darāti noch kontrollieren. Sāeru befindet sich mit dem Großteil seiner Anhänger außerhalb der Stadt und agiert im Interesse der Assyrer. In der Stadt selbst bereiten seine heimlichen Verbündeten den Machtwechsel vor.

95 D.h. einer der Männer des Säeru.

96 Das heißt wohl, dass zuerst ein Agent des Sā'eru unerkannt auf normalem Wege in die Stadt kommen soll, um den genauen Zeitpunkt der Aktion zu verabreden. Zur Vermeidung vorzeitiger Entdeckung durfte der vorbereitete Mauerdurchbruch erst dann endgültig erfolgen, wenn draußen die Truppen des Sä'eru bereitstanden.

97 Wohl der Name für jenen Abschnitt der Stadtbefestigungen, auf dessen Innenseite sich die fraglichen Häuser befanden, in denen der Durchbruch vorbereitet wurde.

98 Fuchs/Parpola (2001, Nr. 199: 5-r.13). 
lich improvisieren mussten, meint niksu hier wohl keinen Tunnel, sondern eher einen Mauerdurchbruch. Für beides wären Häuser geeignet gewesen, die sich unmittelbar an die Stadtmauer lehnten.

Wenn im andern Fall der von Salmanassar in Gannanate eingeschlossene Marduk-bēl-usāte „wie ein Fuchs durch ein Loch (ina pilse) entkam, "99 so wird pilšu entweder einen unterirdischen Geheimgang, eben einen Fuchsbau, beschreiben, oder es handelt sich auch hier wieder um einen auf der Innenseite der Stadtmauer heimlich vorbereiteten Mauerdurchbruch, der erst im Augenblick der Flucht vollendet wurde und dem Eingeschlossenen die Möglichkeit zum Entkommen an einer Stelle bot, die der Belagerer deshalb weniger aufmerksam bewachte, weil er dort eine Flucht glaubte ausschließen zu können.

\section{Anhang 3: Belagerungsturm und Belagerungsdamm}

Der im Mittelalter verwendete Belagerungsturm, der an die Mauer herangeschoben wurde, um den Angreifern vermittels einer angebrachten (Fall)brücke direkten Zugang zu den Wehrgängen zu ermöglichen, lässt sich weder auf den assyrischen Reliefdarstellungen noch in den Kriegsberichten nachweisen.

Reliefs der Zeit Assurnasirpals II. (Abbildungen 1 und 2) zeigen, dass der assyrische Belagerungsturm ${ }^{100}$ kein eigenständiges Angriffsmittel sondern eine Unterstützungswaffe war, die den Bogenschützen als Plattform diente, damit sie aus erhöhter Position die Wehrgänge bestreichen konnten. Auf den Assurnasirpal-Reliefs wird die Festungsmauer jeweils im Vordergrund von einem Rammbock attackiert, der durch ein gepanzertes Fahrzeug geschützt ist, während im Hintergrund und teilweise von diesem Fahrzeug verdeckt, ein mit Bogenschützen bemannter Turm zu sehen ist, der leicht nach hinten versetzt steht. ${ }^{101}$ In den Textquellen zeigt sich die Unterstützungsfunktion des Turmes darin, dass derselbe nie

99 Grayson $(1996,30 \vee 1)$.

${ }^{100}$ Der Belagerungsturm wird im neuassyrischen und im neubabylonischen Reich nicht als $\operatorname{dimtu}$ (AHw $171 \operatorname{dimtu}(m)$ I 2.c, CAD D $145 \operatorname{dimtu} 1$ 1.c) sondern mit dem Wort șăb pìtu bezeichnet (AHw 1082 șāp/bitu und CAD S 97 șāpitu). Zur Verwendung im neubabylonischen Reich durch die Gruppen Nabopolassars und Nebukadnezars II. siehe Grayson (1975, 93f.: 35-36, 100: 22).

${ }^{101}$ In Abbildung 1 (Barnett 1975, Tafel 30) besitzt das mit dem Rammbock ausgestattete Fahrzeug vorne einen turmartigen Aufsatz, der mit einem Kuppeldach abschließt. Ein solcher Kuppelaufsatz ist auch in Abbildung 2 (Barnett 1975, Tafeln 28 und 29) auf der Vorderseite des Fahrzeuges im Umriss angedeutet. Hier aber wird die Kuppel durch ein Götteremblem (Bogenschütze mit Hörnerkrone) teilweise verdeckt. 
allein, sondern stets in Kombination mit einem anderen Mittel begegnet. In den erwähnten Reliefabbildungen Assurnasirpals II. deckt er den Rammbock, die Inschriften dieses Königs verbinden ihn mit dem Rammbock und dem Tunnel bzw. Mauerdurchbruch. ${ }^{102}$ Exakte Entsprechungen für beide Kombinationen lassen sich bereits in der Mari-Korrespondenz finden: Einmal bringt Išme-Dagan einen Turm (dimtum) und einen Rammbock (jašbum) zum Einsatz, bei einer anderen Belagerung lässt er zuerst einen Turm aufstellen und bringt anschließend (durch den Turm gedeckt) die Mauer durch Anlage von Stollen bzw. durch Mauerdurchbruch (ina pilši) zum Einsturz. ${ }^{103}$

Die hethitische Erzählung von der Belagerung der Stadt Uršu beschreibt einen Belagerungsdamm und erwähnt obendrein den Belagerungsturm, nennt also zwei verschiedene Techniken, den Rammbock bei seinem Einsatz zu schützen. ${ }^{104}$ Nachdem „sie“"105 den zunächst offenbar ohne Deckung eingesetzten Rammbock zerstört haben, befiehlt der darob wenig begeisterte König, das ruinierte Gerät durch einen neuen Rammbock hurritischer Art zu ersetzen. Gleichzeitig ordnet er an, Erde zu einem Berg (huršānu), d.h. zu einem Belagerungsdamm aufzuschütten, der nach seiner Fertigstellung von den eigenen Truppen besetzt werden soll, um auf diese Weise künftigen Anschlägen des Gegners wirkungsvoll begegnen zu können. Außerdem ist der Herrscher bemüht, die Lieferung der bewährten Kombination von Belagerungsturm samt Rammbock zu forcieren.

Im neuassyrischen Reich begegnen diese beiden Techniken nicht gleichzeitig, sondern nacheinander. Lässt sich der Belagerungsturm im 9. Jahrhundert mehrfach belegen, so fehlt er in der zweiten Hälfte des 8. und im 7. Jahrhundert vollständig sowohl in den bildlichen wie in den schriftlichen Quellen. Auch in den Anfragen an den Sonnengott sucht

102 ina pilši nāpili șābīte „,durch Tunnel/Mauerdurchbruch, Rammbock, Belagerungsturm“ (Grayson 1991, 216 iii 53). Vgl. ina pilši șāpite u nēpeše „,durch Tunnel/Mauerdurchbruch, Rammbock und Belagerungsgerät" (Grayson 1991, 220 iii 111). In einer Inschrift Šamši-Adads V. allerdings erscheint der Rammbock ausnahmsweise ohne schützenden Belagerungsturm: ina pilši u nāpili simmilti ,durch Tunnel/Mauerdurchbruch und Rammbock, Leiter" (Grayson 1996, 191 iv 15'f.).

${ }^{103}$ Dossin (1950, 131: 11-13 und 135: 6-10 = Durand 1998, 528 und 529). In Dossin et al. (1964, 146: 15-18 = Durand 1998, 606) wird vorgeschlagen, gleichzeitig einen Turm und einen Rammbock herzustellen, offenbar wurde der eine nur in Verbindung mit dem andern als nützlich erachtet. Dass der Rammbock nicht etwa Bestandteil des Turmes war, geht aus dem Brief Jean (1950, 7 = Durand 1998, 465) hervor, der vom Transport gleich mehrerer Türme zusammen mit nur einem einzigen Rammbock handelt. ${ }_{104}$ Zum folgenden siehe Beckman (1995, 24: 13'-18' und 28'-33').

105 Gemeint sind doch wohl die Verteidiger der Stadt, nicht die Leute des Königs. 
man nach ihm vergeblich. Der Belagerungsdamm (arammu, ${ }^{106}$ selten auch birūtu oder huršānu, s. u.) nimmt in den Berichten nunmehr den bisherigen Platz des Turmes ein, der herkömmlichen Kombination von Turm und Rammbock entspricht nun das Paar Belagerungsdamm und Rammbock. Der Zweck von Belagerungsturm und -damm war derselbe, beide sollten dem Rammbock Deckung geben.

Den Belagerungsdamm hat man sich als einen in Schussweite der belagerten Festung künstlich angelegten Hügel oder Berg vorzustellen, der es den Fernkämpfern des Angreifers ermöglichte, die Verteidiger aus erhöhter Position beschießen zu können, um sie dadurch von den Wehrgängen zu vertreiben. Der Belagerungsdamm musste darum höher sein als der angegriffene Mauerabschnitt, und in der Tat ließ Sargon II. den gegen Dür-Jakin errichteten Belagerungsdamm ausdrücklich so hoch aufführen, dass er schließlich die Mauer(krone) überragte. ${ }^{107}$ Die Höhe, das entscheidende Merkmal einer solchen Konstruktion, begegnet auch als Synonym für den Belagerungsdamm: Der Hethiterkönig lässt vor Uršu den bereits erwähnten „Berg“ (huršānu) aufschütten, Tiglatpileser III. will die Stadt Dūr-Balīhāja „durch Höhe und Belagerungsgerät" (ina bìrūti u nēpeši $)^{108}$ bezwungen haben, was der sonst üblichen Kombination von Belagerungsdamm und Rammbock entspricht.

Der Ablauf eines Angriffes mit Belagerungsdamm und Rammbock lässt sich anhand der diesbezüglichen knappen Bemerkungen in den Königsinschriften in groben Umrissen rekonstruieren: In harter, mühseliger Arbeit (marșiš pašqiš) wurde das Baumaterial aufgeschichtet ( $\check{s} a \bar{a} \bar{a} k u$ ) und festgestampft (kabāsu, šukbusu). War der Damm fertiggestellt, konnten von dort oben die Bogenschützen in Aktion treten, wodurch dem Verteidiger „das Besteigen seiner Stadtmauer zum Schrecken“ wurde. ${ }^{109}$ Nun

106 AHw 64 arammu(m) 1, CAD A/II 227 f. arammu 2.b.2'.

${ }^{107}$ Fuchs (1994, 165f.: Ann.358f.). Dieser Passus widerlegt Meissner (1919), der im Belagerungsdamm die künstliche Rampe oder Bahn sehen wollte, die angelegt werden musste, um den Rammbock an die Mauer heranschieben zu können. Eine Rampe, die höher war als die Mauer selbst, wäre zu solchem Zweck sinnlos gewesen. Die in Lahiš ergrabene Rampe hat nur den Mauerfuß erreicht, siehe Ussishkin (1982, 50 ff.).

108 Tadmor (1994, 162 Summ.7:21 mit Anmerkung), bzw. Borger (1964, 54) zu dem Adjektiv biru, „hoch“, „tief“.

109 Der Bau des Belagerungsdammes wie auch seine unmittelbare Wirkung ist ausführlich in Asarhaddons Gottesbrief beschrieben, der über die Belagerung der Stadt Uppumu berichtet, siehe Borger (1967, 104 i 37-38). Als Baumaterial wurde alles verwendet, was sich in der Umgebung finden ließ, neben der üblichen Erde auch Holz und Stein, sofern vorhanden. Der Holzanteil des Dammes, den Asarhaddon gegen Uppumu errichten ließ, war so groß, dass sich die Verteidiger Chancen ausrechneten, ihn ver- 
war der Zeitpunkt gekommen, den Rammbock heranzuführen (qitrub/ qurrub šupî), ${ }^{110}$ der mit seinen Stößen (mihiș šupê) die Mauer zertrümmern sollte. ${ }^{111}$ Wollte oder konnte man keinen Rammbock einsetzen, so war es im Schutze des Belagerungsdammes ebenso möglich, die Mauer stattdessen zu unterminieren oder sie mit Handwerkzeugen wie Hacken und Stemmeisen direkt anzugehen (ina niksi ina pilši, siehe oben Anhang 2). Sobald die Bresche geschlagen war, folgte der Angriff des Fußvolkes (mithus zu $\bar{u} k$ šepe $) .112$ Das entscheidende Ereignis innerhalb eines solchen Belagerungsablaufes war die Fertigstellung des Belagerungsdammes, denn damit galt das Schicksal der Festung als besiegelt, ihr Fall stand unmittelbar bevor. So zeigte sich etwa, kaum dass Sargons Belagerungsdamm vor Dūr-Jakin hoch genug emporgewachsen war, Mardukaplu-iddina zu Übergabeverhandlungen bereit und räumte schließlich die Stadt gegen Zusicherung freien Abzuges. ${ }^{113}$ Und den König von Upumu soll die Verzweiflung überwältigt haben, nachdem sein Versuch, die assyrischen Bauarbeiten durch Brandanschlag und Ausfall zu stören, gescheitert war und er schließlich den Belagerungsdamm Asarhaddons vollendet sah. ${ }^{114}$

Gegenüber dem Belagerungsturm bot der Belagerungsdamm mehrere Vorteile. Er ließ sich dank seiner Masse weniger leicht zerstören als ein hölzerner Turm, die Herstellung war in technischer Hinsicht unkompliziert, und er ließ sich mit entsprechendem Arbeitsaufwand so weit vergrößern, dass er ungleich mehr Schützen Platz bieten konnte, als dies selbst mit mehreren Belagerungstürmen möglich gewesen wäre. Zur Errichtung eines solchen Bauwerkes musste der Angreifer lediglich über Arbeitskräfte in genügender Anzahl verfügen, um die enormen Erdarbeiten in akzeptabler Frist bewältigen zu können. Gerade diese Voraussetzung aber vermochte das an Umfang unerhört große assyrische Heer des 8. und 7. Jahrhunderts leicht zu erfüllen. Nicht umsonst verweisen die Assyrerkönige dieser Zeit voll Stolz auf die „Heeresmassen Assurs“ (ummānāt Aššur gapšāti).

Dennoch waren der Anwendbarkeit des Belagerungsdammes durch das Gelände eindeutige Grenzen gesetzt. Gegen eine Festung, die auf

brennen zu können. Siehe Borger (1967, 104 i 37 (Materialien) und ii 1-7 (Versuch der

Verteidiger, den Damm in Brand zu stecken).

110 ina šukbus aramme u qitrub šupî (Borger 1979, 74 iii $21 \mathrm{f}$.), qurrub šupê (Borger 1979, 80 V 16 und Na'aman 1974, 26: 8).

111 ina šukbus aramme mihis supê (Borger 1996, 180/219 Prisma E Stück 12 Zeile 21).

112 Borger (1979, 74 iii 22, 80 V 17), Na'aman (1974, 26: 8) mit Frahm (1997, 229 ff.).

113 Fuchs (1994, 165-167: Ann. 358-359a).

114 Borger (1967, 104 ii $14 \mathrm{ff}$.). 
einem Berg oder selbst auf einem Hügel lag, der nach allen Seiten hin abfiel, ließ sich dieses Mittel nicht gebrauchen, denn der Arbeitsaufwand zur Errichtung eines solchen Dammes stieg nicht nur proportional zur Erhöhung des Dammes an, sondern vermehrte sich mit zunehmender Höhe sehr viel schneller, in geometrischem Wachstum. Brauchbar war der Belagerungsdamm nur in der Ebene oder dort, wo die Befestigungsanlagen der belagerten Siedlung an wenigstens einer Stelle soweit zugänglich waren, dass man sie ohne Überwindung nennenswerter Höhendifferenz erreichen konnte.

\section{Anhang 4: Nicht Können oder nicht Wollen?}

Zuletzt ist noch auf das Modell einzugehen, das Karen Radner (2004) im Hinblick auf die Beziehungen der Assyrer zu bedeutenden Handelsstädten vorgestellt hat: „Assyrien förderte als Schutzmacht gezielt einzelne Warenumschlagplätze außerhalb des eigentlichen Reiches und verschaffte ihnen so eine gewinnbringende Vormachtstellung über die Konkurrenz. Die solchermaßen bevorzugten Handelsstädte hatten im assyrischen Reich einen finanzstarken Abnehmermarkt. Assyrien profitierte an den erzielten Gewinnen durch Besteuerung (miksu) und sparte sich den Aufbau eines eigenen Handelsnetzes mit den großen Risiken, die Handelsexpeditionen stets anhaften“ (Radner 2004, 157). Dementsprechend hätte Assyrien also bestimmte wichtige Handelszentren geschont, d.h. auf ihre Annexion bewusst verzichtet, und sie stattdessen als abhängige Klientel- oder Vasallenstaaten weiterbestehen lassen, ,solange die Handelszentren mit Assyrien nicht politisch in Konflikt gerieten." Besonders gedeihlich soll das Verhältnis Assyriens zu Karkemiš und Tyros gewesen sein. Möglich geworden sei es dadurch, dass Assyrien zum Zweck der Überwachung eigene Stützpunkte in deren unmittelbaren Nähe errichtet habe, so Kār-Salmanassar (ehemals Til-Barsip) neben Karkemiš, Kār-Asarhaddon ${ }^{115}$ neben Tyrus. Das Ergebnis nennt Radner eine „Symbiose durch Kontrolle“ (Radner 2004, 157).

Dieses Modell steht in klarem Widerspruch zu den in vorliegendem Artikel vertretenen Ansichten, denn wenn Assyrien sowohl Karkemiš

${ }^{115}$ Kār-Asarhaddon ist gegen Radner $(2004,160)$ nicht mit Sidon identisch, denn diese Stadt hat Asarhaddon zerstören lassen. Anschließend, ,versammelte ich alle Könige von Hatti und von der Meeresküste, ließ an einem anderen Ort eine Stadt errichten und nannte diese Kār-Asarhaddon“ (Borger 1956, 48 Nin.A ii 80-82). 
wie Tyros tatsächlich aus merkantilem Kalkül absichtlich hat weiterbestehen lassen, so hätten diese beiden ihre Fortexistenz eher assyrischer Gnade als ihrer eigenen Verteidigungsfähigkeit zu verdanken gehabt, und Assyriens Fähigkeiten im Belagerungskrieg wäre womöglich sehr viel höher zu veranschlagen als es oben erwogen wird. Folgende Punkte in Radners Darstellung sind zu hinterfragen:

1) Hat das Verhältnis zu Assyrien Karkemiš tatsächlich eine herausragende Rolle im syrischen Handelsnetz eingetragen? Radner zufolge war Karkemiš nicht nur „der bedeutendste Warenumschlagplatz und Verkehrsknotenpunkt am mittleren Euphrat“ bzw. „für Assyrien der wichtigste Zwischenhändler nach Anatolien und an die Mittelmeerküste," sondern, mehr noch, „Karkemiš' Stellung als Handelsumschlagplatz blieb weltweit herausragend" und zwar dank der Symbiose mit Assyrien und dessen gezielter Förderung (Radner 2004, 157 f.).

Angesichts solcher Begünstigung müsste der König von Karkemiš die anderen syrischen Kleinkönige an Reichtum bei weitem übertroffen haben. Aber wie lässt sich wirtschaftlicher Erfolg einer ganzen Stadt für diese Epoche überhaupt quantifizieren oder vergleichen? Die einzigen Quellen, die wenigstens den Versuch gestatten, sind die Beuteangaben in assyrischen Königsinschriften. Sie aber zeigen, dass die Gold- und Silbermengen, die Sargon II. im Jahre 717 in Karkemiš erbeutet haben will, keineswegs einzigartig waren, sondern ihrem Umfang nach den Beutemengen oder Zahlungen aus anderen Kleinreichen derselben Region, wie Bìt-Agūsi, Unqi, Damaskus, Tyros oder dem anatolischen Tabāl, durchaus entsprachen:

\begin{tabular}{|l|l|l|}
\hline $\begin{array}{l}\text { Gold } \\
\text { (Talente) }\end{array}$ & $\begin{array}{l}\text { Silber } \\
\text { (Talente) }\end{array}$ & Herkunft \\
\hline 11,5 & 2100 & Beute aus Karkemiš (Winckler 1889, t48: 21-22) \\
\hline 30 & 2000 & Beute aus Bï-Agūsi (Tadmor 1994, Summ.9: 24') \\
\hline 20 & {$[\mathrm{x}]$} & Beute aus Unqi (Tadmor 1994, Summ.9: 26')* \\
\hline 100 & 1000 & Zahlung des Mari von Damaskus (Grayson 1996, 209: 20) \\
\hline- & 2000 & ditto (Grayson 1996, 211: 6) \\
\hline 20 & 2300 & ditto (Grayson 1996, 213: 18) \\
\hline$(1) 50$ & 2000 & $\begin{array}{l}\text { Zahlung des Metenna von Tyros (Tadmor 1994, Summ.7: } \\
16^{\prime}, \text { Summ.9: r.26) }\end{array}$ \\
\hline 10 & 1000 & Zahlung des Hullī von Tabāl (Tadmor 1994, Summ.7: 15') \\
\hline
\end{tabular}

* vgl. Tadmor (1994, 56: Ann.25: 9'). 
Mit Ausnahme von Tabāl, das über eigene Silbervorkommen verfügte, können die übrigen Länder und Städte ihr Silber nur durch Handel erworben haben. Folglich waren Bīt-Agūsi, Unqi und Damaskus hinsichtlich ihrer Wirtschaftskraft und wohl auch ihres Handelsvolumens mit Karkemiš gleichauf. Letzteres kann also keine irgendwie einzigartige oder beherrschende Stellung im syrischen Handelsnetz eingenommen haben und war wohl nur eines unter mehreren bedeutenden Handelszentren der Region. Überdies führt die Liste nur jene Städte und Reiche auf, über die uns Zahlen überhaupt vorliegen, und es wäre zu fragen, warum Samaria, Sidon, Arwad, Hama, Adana in Que, Sam'al, Marqasi, Melidu und Kummuhi, über die keine solchen Angaben erhalten sind, die jedoch allesamt dem Handel günstig gelegen waren, wirtschaftlich weniger erfolgreich gewesen sein sollten als die in der Liste genannten!

Das Verhältnis zu Assyrien hat Karkemiš jedenfalls keinen ökonomischen Vorteil oder Vorsprung gegenüber den übrigen Handelszentren Syriens verschafft. Und da ausgerechnet Bìt-Agūsi und Damaskus, die beiden hartnäckigsten Gegner Assyriens westlich des Euphrat, der Liste zufolge nicht minder reich gewesen sein dürften wie Karkemiš, so scheint es für einen syrischen Kleinkönig wenigstens in finanzieller Hinsicht gar keinen Unterschied gemacht zu haben, ob er ein Vasall oder ein Feind Assyriens war. Im Hinblick auf die Auswirkung der Vasallität an sich ist dies eine durchaus positive Feststellung, die aber gleichwohl hinter den von Radner geäußerten Vermutungen weit zurückbleibt. Eine gewinnbringende Vormachtstellung hat Karkemiš im Handel nicht gehabt.

2) Kann das Verhältnis zwischen Karkemiš und Assyrien als Symbiose gelten? Wenn Karkemiš schon keine erkennbaren ökonomischen Vorteile aus seiner Beziehung zu Assyrien zog, so könnte es doch wenigstens politisch von Assyrien in besonderer Weise gefördert worden sein. Karkemiš stand Salmanassar III. 858 bis 857 und nach seiner vorläufigen Unterwerfung im Jahre 857 mindestens 849 bis 848 als Feind gegenüber, ${ }^{116}$ so dass hier schwerlich von einem guten Verhältnis gesprochen werden kann. Und auch in einer Inschrift Šamšī-Adads V. wird Karkemiš nur erwähnt, weil Kār-Salmanassar dieser Stadt gegenüberlag, ${ }^{117}$ da aber einer Inschrift Adad-nārārīs III. zufolge sämtliche Könige von Hatti zur Zeit Šamši-Adads V. „stark geworden“ seien und ihre Zahlungen eingestellt hätten, ${ }^{118}$ war dieses Gegenüber wohl kein herzliches Miteinan-

\footnotetext{
116 Siehe wiederum Yamada (2000, 78f. H und I, 110 E', 166 B und 170 B).

117 Grayson (1996, 184 ii 9-10).

118 Grayson (1996, 208f.: 13-18).
} 
der. ${ }^{119}$ In den Inschriften Adad-nārārīs III. wird Karkemiš nicht namentlich erwähnt und müsste dort unter den genannten „Königen von Hatti“ subsumiert sein; in den Tributlisten Tiglatpilesers III. erscheint Pisiris von Karkemiš als ein Tributzahler unter vielen anderen. Somit gibt es nicht auch nur einen einzigen Hinweis, dass unter den assyrischen Vasallenkönigreichen in Syrien Karkemiš zu irgendeiner Zeit eine bevorzugte oder begünstigte Stellung genoss oder dass sein Verhältnis zu Assyrien außergewöhnlich gewesen wäre.

Fügt man außerdem noch die oben getroffene Feststellung hinzu, dass Karkemiš zum Zeitpunkt seines Falles auch keineswegs reicher gewesen ist als andere Zentren des syrischen Raumes, so folgt aus alledem, dass Karkemiš zwar zu den bedeutendsten Vasallen Assyriens zu rechnen war, dass aber seine Stellung unter diesen weder eine einzigartige noch eine bevorzugte gewesen sein kann.

3) War es für Assyrien in jedem Falle lohnender, einen reichen Handelsplatz als Vasallen fortbestehen zu lassen anstatt ihn zu plündern? Wenn assyrische Herrscher reiche Handelsplätze tatsächlich mit Bedacht als Vasallen bestehen ließen, selbst dann, wenn sie in der Lage gewesen wären, deren unabhängige Existenz zu beenden, so müssten die Einkünfte, die ihnen aus dem fortbestehenden Handelsplatz zuflossen, wenigstens mittelfristig bedeutender gewesen sein als die Beute, die sich bei der Eroberung und Plünderung ergab. Mit Blick auf Tyros vertritt Radner $(2004,161)$ diese Meinung, denn es sei „klar, dass Assyrien aus einem funktionierenden tyrischen Handel seinen Nutzen zog und keinerlei Interesse daran hatte, den Handelsumschlagplatz zu zerstören oder selbst zu übernehmen“, und auch die Beziehung zu Karkemiš sei eine „profitable Koexistenz" gewesen, die von assyrischer Seite nur wider Willen, aufgrund der Einmischung des Midas von Phrygien, beendet worden sei (Radner 2004, 159).

Gerade im Falle von Karkemiš aber lässt sich die Tributsumme, die von der bestehenden Stadt gezahlt wurde, mit der Beute vergleichen, die ihrem Eroberer in die Hände fiel, zumindest wenn man sich dabei auf die angegebenen Edelmetallmengen beschränkt. Salmanassar III. erlegte Karkemiš im Jahre 857 einen jährlichen Tribut von 1 Mine Gold und 1

119 Radner weist in Anm.21 ihres Artikels darauf hin, dass in Briefen der Zeit Sargons das Gegenüber assyrischer und urarțäischer Stützpunkte in derselben Weise skizziert wird, wie es in der genannten Inschrift Šamšì-Adads V. im Falle von Til-Barsip/Kār-Salmanassar und Karkemiš geschieht. Von Kār-Salmanassar aus hat man also Karkemiš auf dieselbe argwöhnische Weise belauert, wie dies später die Statthalter Sargons gegenüber dem urarțäischen Feind taten. 
Talent Silber auf. ${ }^{120}$ Sollte die Höhe der Zahlung bis zur Zeit Sargons II. noch dieselbe geblieben sein, ${ }^{121}$ so wären 2100 Jahreszahlungen an Tribut nötig gewesen, um an Silber dasselbe zusammenzubringen, was 717 in einem einzigen Jahr erbeutet wurde. Sargon und seine Nachfahren hätten also theoretisch bis ins späte Mittelalter hinein sparen müssen! Aber selbst dann, wenn Assyrien rücksichtsloser mit seinen Forderungen gewesen sein sollte, wenn der Tribut bis zum Ende des 8. Jahrhunderts auf das Zehn- oder selbst das Hundertfache erhöht worden wäre, so hätte Sargons verbleibende Lebenspanne noch immer nicht ausgereicht, um auf dem Tributwege die erbeutete Silbermasse anzuhäufen! Es ist also nur zu verständlich, dass sich Sargon dafür entschied, Karkemiš bei der nächsten sich bietenden Gelegenheit zu kassieren. ${ }^{122}$

Es war die Schatzbildung, die von allen altorientalischen Herrschern betriebene Thesaurierung, die es von vornherein verhinderte, dass sich der Fortbestand gerade einer reichen Handelsstadt für Assyrien mehr lohnen konnte als deren Ausplünderung. Karkemiš war in den Augen der Assyrerkönige ganz sicher kein Partner in einer Symbiose, sondern ein zum Bersten gefülltes Sparschwein, das nur darauf wartete, geschlachtet zu werden.

4) Waren Handelszentren für Assyrien in fiskalischer und handelspolitischer Hinsicht grundsätzlich nur solange wertvoll, als sie selbstverwaltete Vasallen blieben? Abhängige Handelszentren waren nach Radner für die Assyrer im Hinblick auf die Organisation des Außenhandels wichtig: „Assyrien profitierte an den erzielten Gewinnen durch Besteuerung (miksu) und sparte sich den Aufbau eines eigenen Außenhandelsnetzes mit den großen Risiken, die Handelsexpeditionen stets anhaften" (Radner 2004, 157). Dies soll aber nur so lange der Fall gewesen sein, als Städte wie Karkemiš und Tyros selbstregierte Vasallen blieben und nicht etwa ins assyrische Provinzialsystem eingegliedert wurden. Auf den trau-

120 Yamada (2000, 243 sub 12 Annual tribute).

121 Das ist sogar sehr wahrscheinlich, denn Assyrien scheint in dieser Hinsicht sehr beständig gewesen zu sein, hat doch Sargon den nach Hama deportierten Assyrern Tribut in derselben Höhe auferlegt, wie ihn dort schon der König Irḩuleni im 9. Jh. hatte entrichten müssen, siehe Hawkins (2004, 160 B 5-12).

122 Den Verfassern der Inschriften Sargons war es offenkundig unmöglich, Pisiri(s), dem letzten König von Karkemiš, irgendein konkretes Vergehen zur Last zu legen. Erst 707, mithin zehn Jahre nach dem Fall der Stadt, wird in den Annalen aus Khorsabad erstmals behauptet, der König von Karkemiš habe sich mit Mitä von Mušku eingelassen. Führt man sich vor Augen, dass die Aktivitäten des Mitā zu keiner Zeit über Kilikien hinaus nach Osten gereicht haben, so entlarvt sich diese Anschuldigung als fadenscheiniger Vorwand zur Bemäntelung eines Willküraktes. $\mathrm{Zu}$ den Quellen in chronologischer Abfolge siehe Parpola/Radner/Baker (1998ff., 997 sub Pisiri(s)). 
rigen Abstieg von Karkemiš nach dessen Annexion durch Sargon II. wird eigens hingewiesen (Radner 2004, 159). Zwei Schlüsse wären daraus zu ziehen: Erstens müsste die Eroberung einer Stadt durch Assyrien deren unausweichlichen Niedergang bedeutet und die weitestgehende Einstellung jeglicher Handelstätigkeit nach sich gezogen haben. Zweitens wäre Assyrien vor allem deshalb gezwungen gewesen, Handelsplätze bestehen zu lassen, weil es seinen eigenen Kaufleuten samt und sonders an der Risikobereitschaft gemangelt habe, die zu Aufbau und Pflege eigener Handelsverbindungen notwendig war.

Gegen den ersten Schluss spricht, dass Sargon II. jonische Piraten mit der Begründung hat bekämpfen lassen, dass diese den Handel sowohl von Tyros wie auch den von Que störten.123 Also muss doch der Handel von Que, wenn er hier ausdrücklich neben dem tyrischen erwähnt wird, noch immer einen beachtlichen Stellenwert besessen haben, und zwar obwohl sich Que zu dieser Zeit schon unter direkter assyrischer Herrschaft befand. Dieses Beispiel zeigt, dass die Annexion eines Handelsplatzes und seine Umwandlung in eine Provinz keineswegs zwingend zur Beendigung seiner merkantilen Aktivitäten führen musste.

Der zweite Schluss wird sich weder beweisen noch auch begründen lassen, doch selbst wenn den Assyrern die ihnen damit unterstellte grundsätzliche unternehmerische Trägheit tatsächlich zueigen gewesen sein sollte, so waren da immer noch der riesige assyrische Wirtschaftsraum und in Gestalt des assyrischen Hofes und des assyrischen Heeres zwei Konsumenten von nie dagewesener Kaufkraft, die mit enormen Absatzmöglichkeiten für Waren aller Art Kaufleute von überall her anlockten. Selbst Länder, die weit außerhalb der Reichweite assyrischer Kriegszüge gelegen waren, wie etwa Saba, Dilmun oder Qade, fanden sich dazu bereit, Tribut als „Eintrittsgebühr in den assyrischen Markt“124 zu entrichten. Bei so zahlreichen Anbietern aus nah und fern dürfte das Verschwinden eines einzelnen von ihnen kaum spürbar gewesen sein, denn die überlebenden Konkurrenten werden die entstandene Lücke nur zu gerne ausgefüllt haben. Und mit den freigewordenen Marktanteilen hatten sie selbstverständlich auch die darauf liegenden Einfuhrzölle zu übernehmen, so dass der assyrischen Schatzkammer durch den Anbieterwechsel letztendlich kein Verlust entstanden sein dürfte.

Da im Falle von Karkemiš auch nichts darauf hindeutet, dass es Waren gegeben hätte, die ausschließlich durch Kaufleute gerade dieser Stadt hätten beschafft werden können, war aus der assyrischen Perspektive der

123 Fuchs (1994, Ann. 117-119).

124 So der treffende Ausdruck von Radner (2004, 157). 
Ausfall von Karkemiš im Hinblick auf den Außenhandel ohne weiteres zu verschmerzen. Die Eroberung von Karkemiš war somit eine Katastrophe ausschließlich für die lokale Elite, die bis dahin über die Stadt geherrscht hatte, und damit sicher auch für die dortigen Kaufleute. Für die Schatzkammer Sargons aber, für seine Truppen und die assyrischen Tempel, die an der Beute beteiligt wurden, war die Eroberung ein Gewinn, und in so manch anderem Handelszentrum Syriens wird man sich die Hände gerieben und das Ende von Karkemiš lediglich als die Ausschaltung eines lästigen Konkurrenten betrachtet haben. ${ }^{125}$

Ein Assyrerkönig hatte also sehr wohl Grund, den Handel als solchen sowohl innerhalb wie außerhalb seines Reiches zu fördern und zu schützen, hingegen hatte er kaum Anlass zur Schonung einzelner Handelszentren, die sich nicht in seinem unmittelbaren Besitz befanden.

5) Waren die Stützpunkte Kār-Salmanassar und Kār-Asarhaddon als Symbiosegaranten angelegt? Radners Artikel zufolgte hätte Assyrien die beiden Handelsmetropolen Karkemiš und Tyros durch Errichtung der in der Nähe gelegenen Stützpunkte Kār-Salmanassar bzw. Kār-Asarhaddon überwacht, um dadurch eine "Symbiose durch Kontrolle" zu erreichen (Radner 2004, 157).

Gegen eine solche Annahme spricht eindeutig die Bezeichnung beider Anlagen als kāru, als ,Handelsplätze‘, denn darin drückt sich doch ganz unverblümt die Absicht aus, die Handelsströme aus Karkemiš und Tyros in die beiden unmittelbar daneben gelegenen assyrischen Neugründungen umzuleiten, auf dass der Handelsgewinn vollständig den eigenen Truhen zufließe. ${ }^{126}$ Mag dies auch in beiden Fällen misslungen sein, ${ }^{127}$ so ist doch die Absicht unverkennbar.

125 Auch Radner $(2004,159$ f.) vermutet, die phönizischen Städte hätten ungeheuren Profit aus der Eroberung von Karkemiš gezogen. Man möchte hinzufügen: wohl nicht nur die Phönizier allein.

${ }^{126}$ Auch Radner $(2004,158)$ sieht hinter der Namengebung von Kār-Salmanassar die assyrische Absicht, diese Stadt als Handelszentrum zu nutzen, meint aber, dass dies „, in Symbiose mit dem nur 20 km entfernten Karkemiš “ geschehen sei. Mir ist nicht klar, wie daraus eine Symbiose hätte entstehen können, wo doch jeglicher Handel, der in Kār-Salmanassar getätigt wurde, zwangsläufig das Handelsvolumen des nahen Karkemiš vermindern musste. Es ist doch das Schlimmste, was einem Händler passieren kann, wenn ein anderer in unmittelbarer Nähe dasselbe Geschäft eröffnet! Yamada (2005) geht in seiner Untersuchung zu den kärus des assyrischen Reiches ganz selbstverständlich und meiner Ansicht nach zu Recht davon aus, dass diese allein zum Vorteil Assyriens angelegt worden sind.

${ }^{127}$ So weit bekannt, ist weder Kār-Salmanassar noch Kār-Asarhaddon zu einem überregionalen Handelszentrum geworden, das Karkemiš oder Tyros vergleichbar gewesen wäre. 
Von einer Symbiose kann also keine Rede sein, man wäre viel eher versucht, die Rolle Assyriens als die eines Parasiten zu beschreiben, der sich mit Hilfe eines Stützpunktes so eng als möglich an sein Opfer anklammert, um ihm desto bequemer das Blut aus den Adern saugen zu können. Ein Parasit aber bringt seinen Wirt nicht um, wenigstens nicht vorsätzlich, während Assyrien genau das im Sinn gehabt haben muss: Die Gründung von Kār-Salmanassar bzw. Kār-Asarhaddon stellt den Versuch dar, Karkemiš bzw. Tyros, wenn ihnen militärisch schon nicht beizukommen war, dann eben durch einen Wirtschaftskrieg allmählich zu zermürben. Diese beiden Städte befanden sich folglich nach der Gründung der beiden Stützpunkte nicht in einer Symbiose mit Assyrien, sondern in dessen Würgegriff.

6) Ist Tyros von den Assyrern gleich zweimal und noch dazu mit erstaunlicher Leichtigkeit bezwungen worden? Nach Radner (2004, 161) wäre König Ba'alu von Tyros einmal durch Asarhaddon und ein weiteres Mal durch Assurbanipal besiegt worden, „die entscheidende Rolle spielte hier sicherlich der assyrische Flottenstützpunkt Kār-Aššur-ahu-iddina“ d.h. Kār-Asarhaddon. Zwei Umstände werden in diesem Zusammenhang als überraschend gesehen: Zum einen, dass den Assyrern der Sieg über Tyros verblüffend leicht gefallen sei, viel leichter jedenfalls als später Nebukadnezar II., und zum andern, dass die siegreichen Assyrer Ba'alu von Tyros trotz seines zweimaligen Verrates dennoch als König in Tyros beließen.

Die Berichte von den assyrischen Belagerungsaktivitäten gegen Tyros legen jedoch eine ganz andere Interpretation nahe, die zum Erstaunen über die beiden zuletzt genannten Punkte keinen Anlass mehr gibt. Aus ihren Inschriften geht hervor, dass Asarhaddon und Assurbanipal gegen Tyros nicht mehr vermochten, als es vom Festland abzuschneiden. Zu diesem Zweck haben sie Belagerungsburgen errichtet und dann ganz einfach abgewartet. ${ }^{128} \mathrm{Da}$ in den ausführlicheren Berichten stets nur von der Belagerung selbst, nie aber von der Einnahme oder Plünderung der Stadt oder gar der Gefangennahme des Ba'alu die Rede ist, und da weiterhin Ba'alu anlässlich seiner Unterwerfung nicht persönlich in Ninive erschien, ${ }^{129}$ son-

${ }^{128}$ Borger (1967, 112 Frt. F. Vs.12-14). In 86 AsBbE 7-8 wird zwar die Eroberung von Tyros behauptet, doch kann der Text nur die Einnahme von Städten des Ba'alu, also des Festlandbesitzes vermelden. Die Inschriften Assurbanipals (Borger 1996, 28/216 B § 15) berichten von denselben Aktivitäten wie die Asarhaddons.

${ }^{129}$ Die Inschriften Assurbanipals suchten diese Tatsache zu verschleiern, indem sie angeben, Ba'alu habe seine Kinder und Nichten zu Assurbanipal gebracht, doch verraten Unachtsamkeiten der Schreiber in den Prismen F (I 66) und A (I 59) den wahren Sachverhalt, indem sie anstelle der Form übila „,er brachte“ die Form ušebila „,er ließ brin- 
dern lediglich seinen Sohn und andere Familienmitglieder als Unterpfand seines guten Willens schickte, kann der letztendliche „Sieg“ Assurbanipals in Wahrheit nicht mehr als nur ein Kompromiss gewesen sein.

Es hat also weder Asarhaddon noch Assurbanipal die Insel Tyros mit militärischen Mitteln bezwingen können, was angesichts der Ausrichtung Assyriens hauptsächlich auf das Festland kein Wunder ist. Sowohl der Aufbau wie auch der Unterhalt einer Kriegsflotte gehörte im Altertum zu den organisatorisch wie technologisch anspruchsvollsten Herausforderungen überhaupt, denen eine Regierung sich stellen konnte, von der finanziellen Belastung ganz zu schweigen. Man erinnere sich nur, welche Mühe es während des peloponnesischen Krieges Sparta bereitete, mit Athen auf dem Meer auch nur gleichzuziehen. Assyrien aber war wie Sparta vor allem eine Landmacht und hatte sogar noch weit weniger Grund als Sparta, sich eine eigene Flotte zuzulegen, da so gut wie alle seine Feinde gleichfalls Landmächte oder zumindest vom Festland her angreifbar waren. Bei den wenigen Auseinandersetzungen, die den Einsatz von Seestreitkräften erforderten, griffen die Assyrerkönige daher auf die Flotten abhängiger oder verbündeter Küstenanrainer zurück. Dass im assyrischen Binnenland, wie nicht anders zu erwarten, jegliche technische Kompetenz zur Konstruktion seetüchtiger Schiffe ohnehin fehlte, lässt sich daraus ersehen, dass Sanherib beim Bau wie auch beim Einsatz der Schiffe, vermittels derer er 694 über den persischen Golf hinweg Elam angreifen ließ, auf phönizische Spezialisten angewiesen war.

$\mathrm{Da}$ also eine assyrische Flotte im eigentlichen Sinne gar nicht existierte, so kann Kār-Asarhaddon auch kein assyrischer Flottenstützpunkt gewesen sein. Es hätte allenfalls den Schiffen Verbündeter als Ankerplatz dienen können - sofern man solche noch fand.

Aber gerade die Einrichtung dieses Hafens und der damit verbundene Versuch, den Import soweit als möglich unter Umgehung der Seehandelsstädte zu organisieren, musste diese gegen Assyrien aufbringen. Anlass für den offenen Krieg scheint aber erst Asarhaddons Versuch der Eroberung Ägyptens gewesen zu sein, wodurch nun auch dieses für den phönizischen Handel wichtige Gebiet unter assyrische Kontrolle zu geraten drohte. Wohl zur gleichen Zeit, da ihm Tyros den Kampf ansagte, erhielt Asarhaddon die Mitteilung, dass auch Ikkilū, der König der Inselstadt Arwad, den Blockadekrieg gegen Assyrien eröffnet habe: „Ikkilū

gen" verwenden. Trotz des ausführlichen Berichtes ist außerdem auch keine Rede davon, dass Ba'alu sich dem entwürdigenden Ritual des Füßeküssens habe unterziehen müssen, auf das man in Ninive doch ansonsten den allergrößten Wert legte, vergleiche etwa Borger (1996, 216 B $§ 15$ mit B $\S 16$ und B $\S 17)$. 
lässt keine Schiffe in den Hafen des Königs, meines Herrn, heraufkommen und leitet den gesamten Handel zu sich um. Wer zu ihm kommt, dem hilft er weiter, wer aber zum Hafen von Assyrien heraufkommt, den tötet er und dessen Schiff bringt er auf!" 130

Wie gut hätte Asarhaddon in dieser Situation die Flotte von Sidon gebrauchen können, aber er selbst hatte nur wenige Jahre zuvor durch die Vernichtung von Sidon ${ }^{131}$ den wohl stärksten Rivalen beseitigt, den Tyros und Arwad auf dem Meer besaßen, und damit die maritimen Kräfteverhältnisse zu deren Gunsten verschoben. Der Fehlschlag seiner Politik hätte deutlicher nicht ausfallen können: Asarhaddon hatte es ganz allein sich selbst zuzuschreiben, wenn er jetzt auf dem Meer machtlos war und anstelle von Verbündeten, die ihn hätten unterstützen können, einen praktisch nutzlosen, nach ihm benannten Hafen besaß, vor dessen Einfahrt Blockadeschiffe aus Tyros und Arwad kreuzten!

Die Auseinandersetzung mit Tyros und Arwad verlief in ganz denselben Bahnen:

Da sich in den Inschriften Asarhaddons noch kein Hinweis auf ein Ende der Auseinandersetzung findet, ${ }^{132}$ so vermute ich, dass die Blockade beider im Jahre 671 begann und sich ohne Unterbrechung bis in die Regierungszeit Assurbanipals hinein hinzog.

Dieser hatte bereits als Kronprinz versucht, mit Arwad Verhandlungen aufzunehmen, ${ }^{133}$ doch zeigte sich Ikkilū von Arwad zum Einlenken erst bereit, nachdem Assurbanipal bereits König geworden war. Die Einigung mit Arwad muss in dessen ersten Regierungsjahren geglückt sein, da erstmals die ca. 663-662 verfassten „Large Egyptian Tablets“ davon berichten. ${ }^{134} \mathrm{Da}$ diese Quelle von der Unterwerfung des Ba'alu von Ty-

${ }^{130}$ Luuko/Buylaere (2002, Nr. 127: 15-21).

${ }^{131}$ Borger (1967, 48f. Episode 5).

132 Assurbanipals Prisma C listet Ba'alu von Tyros und Ikkilū (hier: Jakinlū) von Arwad zwar unter den Teilnehmern des ersten Ägyptenfeldzuges auf (Borger 1996, 18 f./212 C II 38 und 46), doch beruht die Liste eindeutig auf einer früheren in den Inschriften Asarhaddons, die die Teilnehmer am Bau des ekal mašarti in Ninive aufzählt (Borger 1967, 60 Nin.A V,55). Die Namen der Könige sind in Assurbanipals Inschrift gegenüber der Liste Asarhaddons zwar aktualisiert, doch beweist dies keinesfalls, dass sie die Verhältnisse zum Zeitpunkt des Ägyptenfeldzuges wiedergibt. Prisma C ist zudem erst nach 649, und damit lange nach dem Ägyptenfeldzug selbst entstanden, zeitlich dem Ereignis näher verfasste Inschriften, etwa die „Large Egyptian Tablets“, bieten dergleichen nicht (Onasch 1994, 103 ff.). Es ist gut möglich, dass die Liste eher dem Stand um 649 als dem der Zeit des ersten Ägyptenzuges entspricht.

${ }^{133}$ Starr (1990, Nr. 89).

134 Onasch (1994, 110 f. LET Rs. 33-36). Zur Datierung der Assurbanipal-Inschriften siehe zuletzt Novotny $(2003,214)$. Zur Datierung der inschriftlich überlieferten Ereignisse der Regierungszeit Assurbanipals siehe Grayson (1980). 
ros noch nichts vermeldet und erst die 648 einsetzende Inschriftenserie entsprechendes berichtet, verharrte Tyros noch länger als Arwad, von 671 bis mindestens 662, in Feindschaft. Die Auseinandersetzung des Ba'alu mit Asarhaddon und Assurbanipal ist damit ihrer Länge nach der angeblich dreizehn Jahre währenden Belagerung von Tyros durch Nebukadnezar II. durchaus vergleichbar.

Tyros und Arwad waren imstande, derartiges durchzustehen, weil sie eben mehr waren als bloße Siedlungen. Als See- und Handelsmächten stand ihnen zu ihrer Versorgung der gesamte Mittelmeerraum offen. Da die Assyrer die beiden Inseln weder zu erreichen noch ihre Versorgungswege zur See abzuschneiden vermochten, war ihnen ein militärischer Sieg unmöglich. Und angesichts der Uneinnehmbarkeit von Tyros und Arwad ist es dann auch kein Wunder, dass sowohl Ba'alu wie auch Ikkilū die Auseinandersetzung mit Assyrien nicht allein physisch, sondern auch politisch überlebten.

7) Kann das Verhältnis zwischen Assyrien und Tyros als Symbiose gelten? Die assyrischen Beziehungen zu Tyros stellen sich insgesamt höchst launisch und wechselhaft dar: Tiglatpileser III. erhielt Tribut von den Königen Tuba'il und Hirummu, letzterer allerdings war zeitweise mit Damaskus verbündet, weshalb Tiglatpileser die Festlandgebiete von Tyros angreifen ließ. König Metenna, vermutlich ein Putschist, erkaufte sich die nachträgliche Anerkennung Tiglatpilesers mit einer exorbitanten Geldsumme. ${ }^{135} \mathrm{Ob}$ Tiglatpilesers Versuch, Tyros zur Teilnahme an einem gegen Ägypten gerichteten Embargo zu bewegen, von Erfolg gekrönt war, ist nicht bekannt. ${ }^{136}$ Josephus zufolge hat Salmanassar V. Tyros wiederum bekämpft, ${ }^{137}$ wohingegen Sargon II. zugunsten von Tyros im Jahre 715 eine Piratenjagd im östlichen Mittelmeer organisierte und König Šilta 707 dazu verhalf, dessen Oberhoheit über die Könige Zyperns wieder herzustellen. ${ }^{138}$

135 Tadmor (1994: Tuba il: 106 St.III A 6. Hirummu: Summ.9: r.5 und 89: Ann.27: 2. Metenna: Summ.7 r.16' mit Anm. und Summ.9 r 26. Unklar: 68: Ann.13: 11). Siehe auch Tadmor (1994, 267 Study D). Tyros war zwar gegen einen direkten Angriff gefeit, doch nur dann, wenn der assyrische Angreifer keinen Verbündeten innerhalb der Stadt selbst fand. Als Putschist musste Metenna jedoch befürchten, dass seine innenpolitischen Gegner womöglich mit Assyrien gemeinsame Sache machten. Daher die hohe an Tiglatpileser gezahlte Summe (siehe dazu die Tabelle weiter oben)!

136 Saggs (2001, 155f.: 3-29).

${ }^{137}$ Siehe Parpola, Radner, Baker (1998ff.) sub Lulî.

138 Siehe Fuchs (1994, Ann.117-119 und Ann.393-398) mit Na'aman (1998). 
Kaum hatte Tyros seine Ziele erreicht, zeigte es sich an der Fortsetzung der Beziehung zu Assyrien nicht mehr interessiert und stellte die Zahlungen ein: Der (assyrische) Mohr hatte seine Schuldigkeit getan, der Mohr konnte gehen. Sanherib mochte sich einer solchen Sichtweise begreiflicherweise nicht anschließen und ließ daher im Jahre 701 einmal mehr die tyrischen Festlandgebiete verwüsten, darunter auch die Tyros gegenüberliegende Festlandsiedlung Ušu ${ }^{139}$ aber auch er konnte Tyros selbst nicht das Geringste anhaben, weshalb in seinen Inschriften die namentliche Erwähnung dieser Stadt im Zusammenhang mit dem eigentlichen Feldzugsgeschehen sorgfältig vermieden wird. Tyros wird nur genannt, weil es Lulî, dem König von Sidon, Asyl bot und ihn später nach Zypern entkommen ließ.140 Anschließend muss sich das Verhältnis jedoch wieder gebessert haben, denn Sanherib konnte beim Einsatz jener Flotte, die 694 gegen Elam fuhr, auf tyrische Seeleute zurückgreifen. ${ }^{141}$

Das gute Verhältnis blieb unter Asarhaddon zunächst bestehen, doch obwohl Tyros bei der assyrischen Annexion Sidons sogar eine bescheidene Gebietserweiterung zugestanden wurde, hat sich König Ba'alu von Tyros, wohl wegen der Gründung des Konkurrenzhafens Kār-Asarhaddon, gegen Assyrien gewandt und sich mit Ägypten verbündet. Auf welche Bedingungen sich Assurbanipal und Ba'alu schließlich geeinigt haben, um den von 671 bis mindestens 662 andauernden Kriegszustand wieder zu beenden, ist nicht überliefert, doch darf vermutet werden, dass auch über die zukünftige Rolle des Hafens Kār-Asarhaddon verhandelt worden ist. ${ }^{142}$

Aber auch dieses Mal sollte die Eintracht nicht von Dauer sein, denn bereits 644 oder kurz danach hielt Assurbanipal über Ušū ein Strafge-

${ }^{139}$ Luckenbill (1924, 29: 42f.).

140 Zur Problematik des Lulî als möglichem König von Tyros siehe die Diskussion von Frahm in Parpola/Radner/Baker (1998ff., sub Lulî).

${ }^{141}$ Frahm $(1997,24)$. Die an Sanheribs Palastbauten beteiligten Tyrer werden zwar zu den Kriegsgefangenen gerechnet (Frahm 1997, T 10/11 28), doch könnte dies der Topik der Königsinschriften geschuldet sein, zu der ja die Vorstellung gehört, der König habe seine Paläste durch die von ihm selbst gefangenen Gegner errichten lassen. Die genannten Tyrer können durchaus bezahlte Fachkräfte gewesen sein.

142 Ein Bēl(-Harrān)-šaddû’a ist als Statthalter von Kār-Asarhaddon wie auch als Statthalter von Tyros und in letzterer Eigenschaft als Eponym des Jahres 650 belegt. Gemeint ist wohl, dass er für die von Assyrien direkt beherrschte Küste Phöniziens zuständig und als Ansprechpartner für Tyros fungierte, siehe Parpola/Radner/Baker (1998ff., 303 sub Bēl-Harrān-šaddû’a 2 und 327 sub Bēl-šaddû'a 4). Die Provinznamen KārAššur-ahu-iddina und Șuru meinen wohl die von Asarhaddon um Sidon eingerichtete Provinz, siehe Radner (2006, 63 sub Șidunu). 
richt $a b,{ }^{143}$ das auch dieses Mal wieder der in Sichtweite, aber eben nicht in Reichweite gelegenen Insel Tyros gegolten haben dürfte. ${ }^{144} \mathrm{Zu}$ dem Zeitpunkt, da die erzählenden assyrischen Quellen nach und nach zu versiegen beginnen, war das assyrisch-tyrische Verhältnis also wieder einmal feindselig. Von einer neuerlichen Versöhnung erfahren wir nichts mehr.

In Anbetracht dessen, dass mit Ausnahme Sargons II. jeder assyrische König von Tiglatpileser III. bis hin zu Assurbanipal irgendwann mit Tyros im Krieg gelegen hat, letzterer sogar mehrfach, mutet der Begriff der Symbiose zur Beschreibung des assyrisch-tyrischen Verhältnisses allzu euphemistisch an. Phasen der Kooperation hat es aber gleichwohl gegeben, zumal Assyrien und Tyros, wie von Radner beschrieben, einander sehr viel bieten konnten: Assyrien bot einen riesigen Absatzmarkt, Tyros dagegen Güter, die es auf Wegen beschaffte, die den landgebundenen assyrischen Kaufleuten verschlossen waren, und wie sich zur Zeit Sargons erwiesen hat, konnten sich darüberhinaus die tyrische Seemacht und die assyrische Landmacht aufs trefflichste ergänzen. Aber man konnte einander auch Schaden zufügen: Assyrien schloss Tyros, wenn nötig, vom Wirtschaftsraum seines Reiches aus und zerstörte die angreifbaren Küstensiedlungen, während Tyros den gesamten Bereich der Mittelmeerküste, den Assyrien beherrschte, zu beunruhigen vermochte.

Wenn Assyrien und Tyros wiederholter Zerwürfnisse zum Trotz immer wieder zueinander fanden, so nicht deshalb, weil Tyros durch Assyrien eben gerade nicht kontrolliert werden konnte, sondern weil sowohl Tyros selbst wie auch sein Seehandel vor dem assyrischen Zugriff vollkommen sicher war. ${ }^{145} \mathrm{Im}$ Wissen um ihre Unangreifbarkeit konnten die Könige von Tyros selbstbewusst auftreten und mussten sich nicht alle Zumutungen gefallen lassen. Unfähig, die jeweils andere in ihrer Existenz bedrohen zu können, war keine Seite in der Lage, ihre Forderungen einseitig zu diktieren. Konflikte ließen sich hier ausnahmsweise einmal nicht mit Gewalt, sondern nur auf dem Wege eines Ausgleiches lösen, der,

${ }^{143}$ Borger (1996, 69/249 A § 81). Die Aktionen gegen Ušu und Akkon (Akkū) werden mit Assurbanipals letzten Araberfeldzügen verbunden, zur Datierung siehe Grayson (1980, 235 sub „Arabs 2“).

${ }^{144}$ Assurbanipal wiederholte hier das oben erwähnte Vorgehen Sanheribs im Jahre 701.

${ }^{145}$ Wenn sich zeitweise ein Repräsentant des assyrischen Herrschers, ein qēpu, in Tyros aufhielt, so nur deshalb, weil seine Anwesenheit in der Stadt geduldet wurde. Dem Vertrag zwischen Ba'alu und Asarhaddon zufolge war der qēpu am ehesten eine Art Botschafter (Parpola/Watanabe 1988, 25: 6'-14'). 
wenn er schließlich gefunden war, jeweils eine weitere kurze Phase vorläufiger Kooperation einleitete.

Aus alldem ist ersichtlich geworden, dass es keinen assyrischen Plan zur Schonung von Handelszentren gegeben hat. Karkemiš verdankte seine lange Überlebensdauer in erster Linie seiner Verteidigungsfähigkeit und sicherlich auch der geschickten Diplomatie seiner Herrscher, während das uneinnehmbare Tyros den offenen Bruch mit Assyrien jederzeit riskieren konnte und zu vielen Malen auch riskiert hat. Assyrien seinerseits war am schnellen Gewinn hier und jetzt, mindestens aber noch zu Lebzeiten des gerade regierenden Herrschers interessiert. ${ }^{146}$ Gegenüber reichen Handelszentren, in denen aufgestapelte Schätze lockten, zeigten sich Assyrerkönige zu Mäßigung und Kompromiss stets nur so lange bereit, als ihnen der ansonsten bevorzugte direkte Weg von Erpressung oder Raub verschlossen war.

\section{Abkürzungen und Literatur}

Abkürzungen gängiger Nachschlagewerke erfolgen nach Borger (1975).

Barnett, R. D./A. Lorenzini (1975): Assyrische Skulpturen im British Museum. Recklinghausen.

Barnett, R. D./E. Bleibtreu/G. Turner (1998): Sculptures from the Southwest Palace of Sennacherib at Nineveh. London.

Bauer, J./R. K. Englund/M. Krebernik (1998): Mesopotamien. Späturuk-Zeit und Frühdynastische Zeit. OBO 160/1. Göttingen.

Beckman, G. (1995): The Siege of Uršu Text (CTH 7) and Old Hittite Historiography, JCS 47, 23-34.

Billerbeck, A./F. Delitzsch (1908): Die Palasttore Salmanassars II von Balawat. Erklärung ihrer Bilder und Inschriften. BA 6/1. Leipzig.

Böhme, et al. (2004): Wörterbuch der Burgen, Schlösser und Festungen. Herausgegeben von Horst Wolfgang Böhme, Reinhard Friedrich und Barbara Schock-Werner in Verbindung mit dem Europäischen Burgeninstitut, einer Einrichtung der deutschen Burgenvereinigung e. V. Stuttgart.

Borger, R. (1964): Rezension zu W. G. Lambert, Babylonian Wisdom Literature, JCS 18, 49-56.

Borger, R. (1967): Die Inschriften Asarhaddons Königs von Assyrien. AfO Beiheft 9. Osnabrück.

Borger, R. (1975): Handbuch der Keilschriftliteratur. Band II. Berlin - New York.

146 Sieht man von der ausgeprägten Sucht nach Verewigung ihres Nachruhmes einmal ab, so dürften assyrische Könige für das, was erst nach ihrem Tod geschehen würde, in etwa dasselbe Interesse aufgebracht haben, das heutige Politiker im Hinblick auf die Folgen ihres Handelns in der Zeit nach der jeweils nächsten Wahl beweisen. 
Borger, R. (1979): Babylonisch-assyrische Lesestücke. 2., neub. Aufl. AnOr 54. Rom.

Borger, R. (1996): Beiträge zum Inschriftenwerk Assurbanipals. Die Prismenklassen A, B, $\mathrm{C}=\mathrm{K}, \mathrm{D}, \mathrm{E}, \mathrm{F}, \mathrm{G}, \mathrm{H}, \mathrm{J}$ und $\mathrm{T}$ sowie andere Inschriften. Mit einem Beitrag von Andreas Fuchs. Wiesbaden.

Botta, P. E. (1849): Monument de Ninive I/II. Paris.

Dossin, G. (1950): Correspondance de Šamši-Addu et de ses fils, transcrite et traduite par Georges Dossin. ARM 1. Paris.

Dossin, G. et al. (1964): Textes divers transcrits, traduits et commentés par G. Dossin, J. Bottéro, M. Birot, Mme M. Lurton Burke, J.-R. Kupper et A. Finet. ARM 13. Paris.

Durand, J.-M. (1998): Les documents épistolaires du palais de Mari. Tome II. Littératures anciennes du Proche-Orient 17. Paris.

Ebeling, E. (1952-1953): Kriminalfälle aus Uruk, AfO 16, 67-69.

Frahm, E. (1997): Einleitung in die Sanherib-Inschriften. AfO Beiheft 26.

Frame, G. (1992): Babylonia 689-627 B.C. A Political History. Istanbul.

Fuchs, A. (1994): Die Inschriften Sargons II. aus Khorsabad. Göttingen.

Fuchs, A. (1998): Die Annalen des Jahres 711 v. Chr. nach Prismenfragmenten aus Ninive und Assur. SAAS 8. Helsinki.

Fuchs, A. (2002): Rezension zu Yamada (2000) (s.u.), JAOS 122, 594-597.

Fuchs, A./S. Parpola (2001): The Correspondence of Sargon II, Part III. Letters from Babylonia and the Eastern Provinces. SAA 15. Helsinki.

Grayson, A. K. (1975): Assyrian and Babylonian Chronicles. TCS 5. Winona Lake, Indiana.

Grayson, A. K. (1980): The Chronology of the Reign of Ashurbanipal, ZA 70, 226-245.

Grayson, A. K. (1991): Assyrian Rulers of the Early First Millennium BC I (1114-859 BC). RIMA 2. Toronto.

Grayson, A. K. (1996): Assyrian Rulers of the Early First Millennium BC II (858-745 BC). RIMA 3. Toronto.

Hawkins, J. D. (1995): The Political Geography of North Syria and South-East Anatolia in the Neo-Assyrian Period, in: M. Liverani (Hg.) Neo-Assyrian Geography. Roma. $87-101$.

Hawkins, J. D. (2000): Corpus of Hieroglyphic Luwian Inscriptions. Volume I: Inscriptions of the Iron Age. Untersuchungen zur indogermanischen Sprach- und Kulturwissenschaft / Studies in Indo-European Language and Culture, Neue Folge / New Series 8.1. Berlin/New York.

Hawkins, J. D. (2004): The New Stele from Hama, in: G. Frame (Hg.), From the Upper Sea to the Lower Sea. Studies on the History of Assyria and Babylonia in Honour of A. K. Grayson. Publications de l'Institut historique-archéologique néerlandais de Stamboul 101. Leiden. 151-164.

Ikeda, Y. (1979): Royal Cities and Fortified Cities, Iraq 41, 75-87.

Jean, C.-F. (1950): Lettres diverses, transcrites et traduites par Charles-F. Jean. ARM 2. Paris.

Lachmann, R. (1975): Memoiren eines Janitscharen oder Türkische Chronik. Eingeleitet und übersetzt von Renate Lachmann. Kommentiert von Claus-Peter Haase, Renate Lachmann, Günter Prinzing. Slavische Geschichtsschreiber 8. Graz/Wien/Köln.

Lipiński, E. (2000): The Aramaeans. Their Ancient History, Culture, Religion. OLA 100. Leuven.

Liverani, M. (1992): Studies on the Annals of Ashurnasirpal II. 2: Topographical Analysis. Quaderni di Geografica Storica 4. Roma.

Luckenbill, D. D. (1924): The Annals of Sennacherib. OIP 2. Chicago. 
Luuko, M./G. Van Buylaere (2002): The Political Correspondence of Esarhaddon. SAA 16. Helsinki.

Mayer, W. (1983): Sargons Feldzug gegen Urartu - 714 v. Chr. Text und Übersetzung, MDOG 115, 65-132.

Meissner, B. (1919): Lexikographisches. 5. arammu, OLZ 22, 112-114.

Millard, A. (1994): The Eponyms of the Assyrian Empire 910-612 B C. SAAS 2. Helsinki.

Na'aman, N. (1974): Sennacherib's „Letter to God“ on his Campaign to Judah, BASOR 214, 25-39.

Na'aman, N. (1998): Sargon II and the Rebellion of the Cypriote Kings against Shilta of Tyre, OrNS 67, 239-247.

Novotny, J. R. (2003): Zahalû-Metal for Marduk's Paramāhu and the Date of Ashurbanipal's E-Prisms, OrNS 72, 211-215.

Onasch, H.-U. (1994): Die assyrischen Eroberungen Ägyptens. Teil 1: Kommentare und Anmerkungen. Teil 2: Texte in Umschrift. Ägypten und das Alte Testament 27. Wiesbaden.

Parpola, S./K. Radner/H. D. Baker (1998ff.): The Prosopography of the Neo-Assyrian Empire. Helsinki.

Parpola, S./K. Watanabe (1988): Neo-Assyrian Treaties and Loyalty Oaths. SAA 2. Helsinki.

Postgate, J. N. (1994): Rings, Torcs and Bracelets, in: P. Calmeyer et al. (Hg.), Beiträge zur Altorientalischen Archäologie und Altertumskunde. Festschrift für Barthel Hrouda zum 65. Geburtstag. Wiesbaden.

Radner, K. (2004): Assyrische Handelspolitik: Die Symbiose mit unabhängigen Handelszentren und ihre Kontrolle durch Assyrien, in: R. Rollinger/C. Ulf (Hg.), Commerce and Monetary Systems in the Ancient World: Means of Transmission and Cultural Interaction. Proceedings of the Fifth Annual Symposium of the Assyrian and Babylonian Intellectual Heritage Project Held in Innsbruck, Austria, October $3^{\text {rd }}-8^{\text {th }} 2002$. Melammu Symposia 5. Wiesbaden, 152-169.

Radner, K. (2006): Provinz C. Assyrien. RIA 11, 42-68.

Roth, J. P. (1999): The Logistics of the Roman Army at War (264 B.C.-A. D. 235). Columbia Studies in the Classical Tradition 23. Leiden/Boston/Köln.

Saggs, H. W. F. (2001): The Nimrud Letters, 1952. CTN 5. British School of Archaeology in Iraq.

Sawyer, R. D. (1993): The Seven Military Classics of Ancient China. Translation and Commentary by Ralph D. Sawyer with Mei-chün Sawyer. Boulder/San Francisco/ Oxford.

Starr, I. (1990): Queries to the Sungod. Divination and Politics in Sargonid Assyria. SAA 4. Helsinki.

Stol, M. (2004): Wirtschaft und Gesellschaft in altbabylonischer Zeit, in: D. Charpin/ D. O. Edzard/M. Stol, Mesopotamien. Die altbabylonische Zeit. OBO 160/4. Göttingen, 643-975.

Tadmor, H. (1994): The Inscriptions of Tiglath-pileser III King of Assyria. Critical Edition, with Introductions, Translations and Commentary. Jerusalem.

Tropper, J. (1993): Die Inschriften von Zincirli. Abhandlungen zur Literatur Alt-SyrienPalästinas 6. Münster.

Ussishkin, D. (1982): The Conquest of Lachish by Sennacherib. Tel Aviv University Publications of the Institute of Archaeology 6. Tel Aviv.

Winckler, H. (1889): Die Keilschrifttexte Sargons nach den Papierabklatschen und Originalen neu herausgegeben. Band II: Texte, autographirt von Dr. Ludwig Abel. Leipzig. 
Yamada, S. (2000): The Construction of the Assyrian Empire. A Historical Study of the Inscriptions of Shalmanesar III (859-823 B.C.) Relating to His Campaigns to the West, CHANE 3. Leiden/Boston/Köln.

Yamada, S. (2005): Kārus on the Frontiers of the Neo-Assyrian Empire, Orient 40, 56-90.

Zorn, R. (1972): Machiavelli. Der Fürst „Il Principe“. Übersetzt und herausgegeben von Rudolf Zorn. Stuttgart. 